Article

\title{
Design of Medium Depth Drainage Trench Systems for the Mitigation of Deep Landsliding
}

\author{
Federica Cotecchia ${ }^{1}\left(\mathbb{D}\right.$, Rossella Petti $^{1}\left(\mathbb{D}\right.$, Dario Milella $^{2, *} \mathbb{D}$ and Piernicola Lollino ${ }^{3} \mathbb{D}$ \\ 1 DICATECh, Polytechnical University of Bari, 70126 Bari, Italy; federica.cotecchia@poliba.it (F.C.); \\ rossella.petti@poliba.it (R.P.) \\ 2 Consulting Engineer, 70126 Bari, Italy \\ 3 IRPI, National Research Council, 70126 Bari, Italy; p.lollino@ba.irpi.cnr.it \\ * Correspondence: d.milella88@gmail.com
}

Received: 8 April 2020; Accepted: 7 May 2020; Published: 10 May 2020

\begin{abstract}
For those slopes where the piezometric regime acts as internal landslide predisposing factor, drainage may represent a more effective mitigation measure than other structural interventions. However, drainage trenches have been generally considered as mitigation measure solely for shallow landslides. More recently, instead, some authors show that the variation in piezometric conditions at large depth is not negligible when medium depth drainage trenches are involved. The paper presents the results of finite element analyses of the transient seepage induced by the installation of systems of drainage trenches of different geometric parameters, and the effect of the drainage system on the stability factor of the slip surface, through $2 \mathrm{D}$ limit equilibrium analyses. The pilot region is the Daunia Apennines, where field studies have led to recognize for most of the landslides a "bowl-shaped" slip surface; the results accounting for the Fontana Monte slope at Volturino (Italy), selected as prototype landslide in the assessment of the stabilization efficacy of deep drainage trench systems, is discussed in the following. The study aims at providing indications about the design of the drainage trenches to reduce the pore water pressures on a deep slip surface of such type.
\end{abstract}

Keywords: drainage trench system; deep landslide; numerical modeling

\section{Introduction}

Historically, the management of landslide risk within chain areas has been hardly sustainable, due to the cost of the engineering interventions [1-5]. This is especially the case in regions where deep slow landslides are widespread, as with deep landslides, the installation of earth retaining structures, representing the traditional mitigation measure, does not provide long-lasting successful mitigation effects. This is because of the large size of deep landslide bodies (maximum depth higher than $30 \mathrm{~m}$, according to Cruden \& Varnes [6]), whose kinematics may be not influenced significantly by the installation of either transversal pile diaphragms (e.g., at the landslide toe, or at mid-height; Figure 1a,b), or longitudinal ones (Figure 1a-c [7]). Eventually, a combination of various retaining diaphragms of significant depth (e.g., piles of more than $40 \mathrm{~m}$ depth in Figure 1), might provide a mitigation effect. Such intervention strategy, though, is recognizably highly expensive and does not necessarily restrain the development of new shear bands and further progressive failure [8]. 

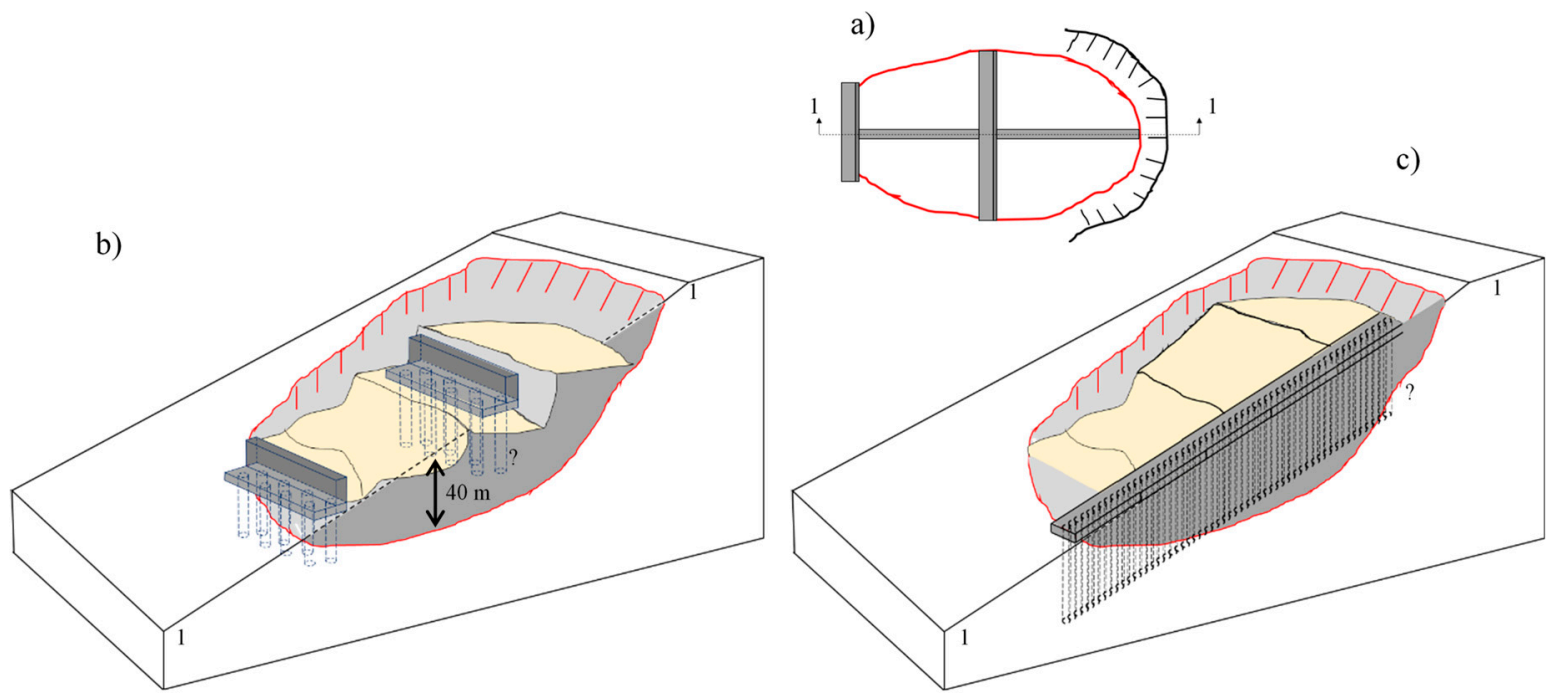

Figure 1. Schematic axonometry of the left portion of the landslide body, whose map is in panel (a), with pile diaphragms (pile depth of $20 \mathrm{~m}$ ) installed along transversal (b) and longitudinal (c) sections.

For those slopes where the piezometric regime acts as landslide predisposing factor [9], drainage may represent a more effective mitigation measure. This is the case, for example, in deep landslides whose displacement rates are related to the piezometric excursions at depth, which are in turn connected to the slope-atmosphere interaction $[10,11]$. However, the traditional drainage systems used for the mitigation of deep landsliding, such as deep drainage wells combined with sub-horizontal drainage pipes (Figure 2 [3,12]), are also costly and of expensive maintenance. Furthermore, the drainage capacity of the sub-horizontal drainage pipes is easily jeopardized by their interaction with the moving landslide, which may cause the pipe failure.

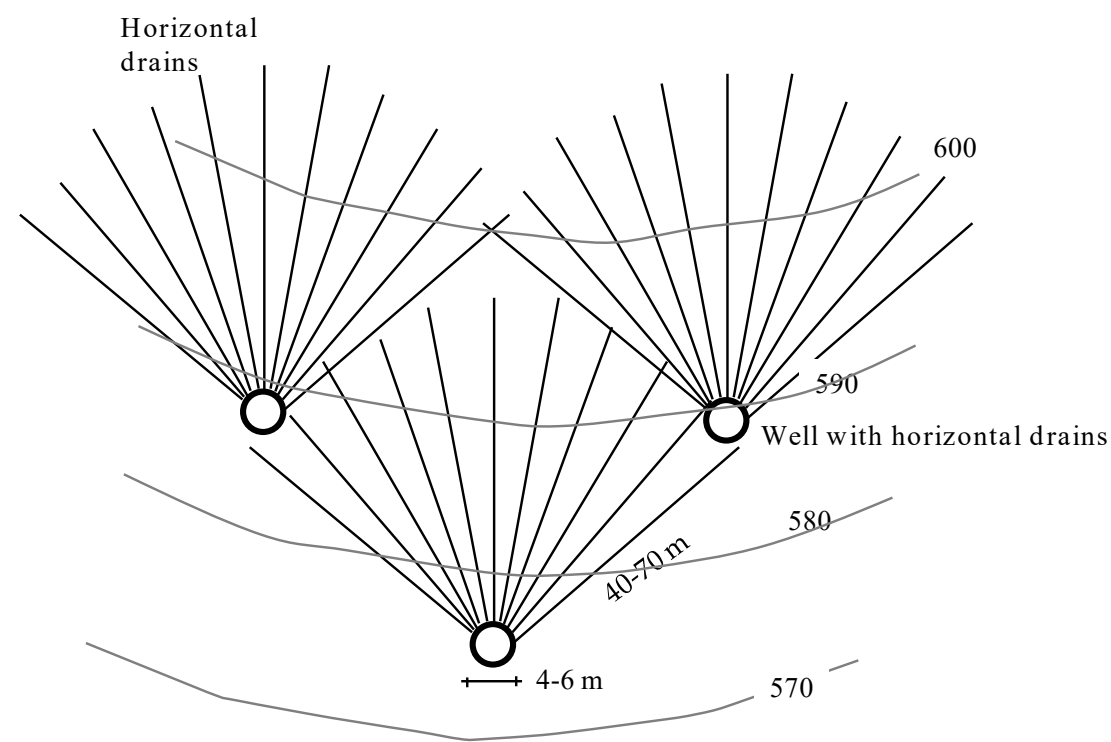

Figure 2. Drainage wells with sub-horizontal drainage pipelines [12].

In the past decades, significant research has been addressed to the hydraulic efficiency of drainage trench systems, which are a robust and relatively not expensive engineering opera [3,12]. In particular, since the late 1970s, research in the field of slope stabilization has paid attention to the effects of drainage trench systems on the slope stability factor, $\mathrm{F}$, in order to optimize the design of such mitigation measure.

However, these drainage trenches have been generally considered as mitigation measure solely for shallow landslides [1,3,13-15]. Based on in situ monitoring after the installation of longitudinal 
drainage trenches, Hutchinson [3] formulated the piezometric head distribution that may be achieved through the use of 2 to $5 \mathrm{~m}$ depth longitudinal trenches (i.e., shallow trenches), for depths only slightly higher than the trench depth. In 1984, Stanic [13] proposed a rational assessment of the influence on the $\mathrm{F}$ value for elongated shallow landslide bodies, assuming the number of trenches to be infinite. Through a parametric study of the variation in drainage steady-state efficiency, E, with the trench spacing S (Figure 3), Stanic provides the prediction of the variation in F, calculated according to the infinite slope model and assuming full saturation of the soils in the whole slope.

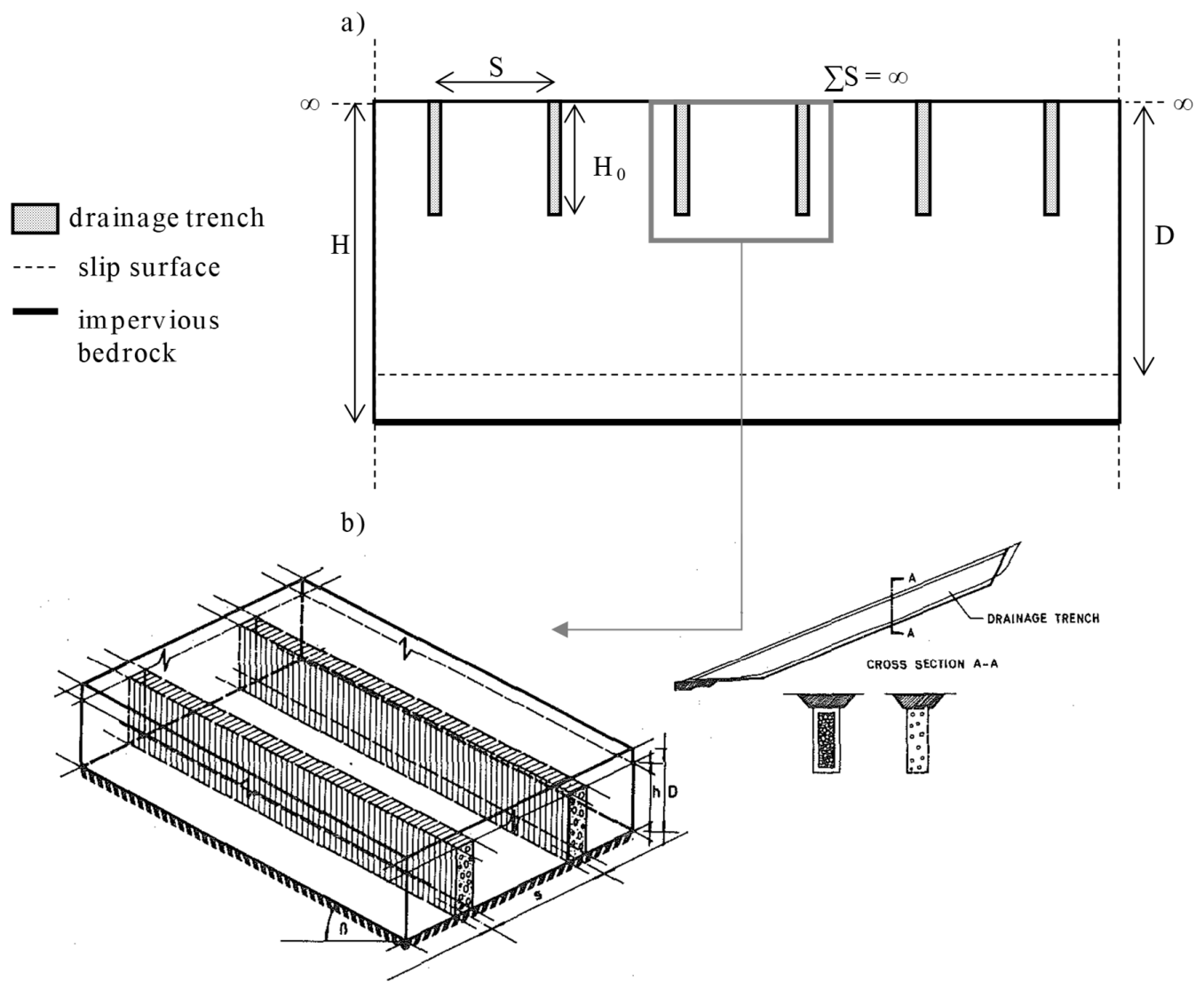

Figure 3. Conceptual model for the calculation of the efficiency performed by Stanic [13] (a) and sketches of the trench system reported by Stanic [13] (b).

Later on, based on the results of a set of parametric numerical analyses performed with reference to the same scheme used by Stanic [13] and sketched in Figure 3, Desideri et al. [16], following Di Maio et al. [17], proposed design charts relating the hydraulic efficiency at small depth of shallow longitudinal trench systems (Figure 3), with their geometric parameters. Moreover, these authors assumed fully saturated conditions; furthermore, they used the Terzaghi-Rendulic approach to compute the transient seepage in a deformable soil and calculated the variation with time of the drainage efficiency, accordingly. More recently, the mitigation effects of medium depth drainage trenches, e.g., of 10-12 m depth, have been formulated for medium depth landsliding [12,18], according to the same modeling approach and calculation scheme used by Desideri et al. [16].

Di Maio et al. [17] highlighted how the drainage efficiency of the trench system is affected by the hydraulic boundary conditions at the ground surface, hence, by the slope-atmosphere interaction. In 2005, D'Acunto \& Urciuoli [19] proposed a parametric numerical analysis (in saturated conditions) of the effects on the stability of shallow landslides of drainage trenches, showing that implementing realistic infiltration at the ground level provides the prediction of larger efficiency than that calculated in presence of a permanent film of water at the ground surface. 
The development of numerical modeling of partially saturated soil behavior has allowed for more accurate predictions of the transient seepage due to rainfall infiltration in slopes. Accordingly, today the transient seepage, triggered by the installation of the trench systems, can be predicted more accurately accounting for partial soil saturation and the slope-atmosphere interaction (i.e., unsteady boundary conditions at the ground level). Furthermore, also the features of the trench system to be input in the analyses could be more realistic than those assumed in all the studies quoted above. In particular, the effects of the trench system have, so far, always been evaluated with reference to shallow depths (no more than 5-6 $\mathrm{m}$ b.g.l.), i.e., where such effects are not much influenced by the transversal extension of the system, $\Sigma S$ (Figure 3), so that an infinite number of trenches have been always assumed in the modeling. Therefore, the seepage has been always modeled making reference to a set of two trenches, as shown in Figure 3b. According to the results of the numerical modeling following such approach, the effects of the drainage trench system on the piezometric conditions at depths larger than twice the trench depth, have always been considered negligible [16]. Therefore, the trench system has always appeared to be an engineering measure not useful for the mitigation of deep landslide activity.

More recently, Cotecchia et al. [11] have proposed the finite element modeling of the transient seepage triggered by a finite number of medium depth drainage trenches, making reference to the whole system ( $n$ being the finite number of trenches). In the analyses, the authors implemented partially saturated conditions above the water table and unsteady boundary conditions at the ground level, to represent the effects of climate. The modeling results provide evidence of piezometric head reductions at large depth which vary with the distance " $x$ " from the plane of symmetry of the system (Figure 4) and are not always negligible. The authors have shown that the maximum drop in piezometric head caused by the trench system occurs below the center of the system; they have then defined such lateral variability in piezometric drop caused by the trench system installation as "group effect". The authors have then shown that the group effect is beneficial for the mitigation of the activity of deep landslides having a "bowl-shaped" sliding surface (see Figure 4a), even in low permeability slopes (e.g., clayey slopes). This is because, if the central plane of the trench system corresponds to the central longitudinal section of the landslide (Figure 4), the group effect makes the reduction in piezometric head at depth be maximum where the bowl-shaped slip surface reaches the maximum depth. In this case, the deepest portion of the slip surface benefits from the "group effect" (Figure 4).

With regard to the technical feasibility of excavating deep trenches in slopes, according to Pun et al. [12], drainage trenches can reach a depth as high as 25-30 m through the currently available technologies. They are usually excavated by means of grab shells, using slurry to sustain the vertical walls of the trench (e.g., polymeric mud). Urciuoli \& Pirone [18] report a couple of innovative construction technologies. In particular, for deep trenches the most recent construction procedure makes use of aerated concrete $[20,21]$ precast panels, manufactured by mixing gravel of high permeability and cement of a good compression strength. This system can also be installed through the excavation and filling of a diaphragm made of secant piles. Its beneficial features are high permeability, the filtering capacity preventing the internal erosion of the filling soils, sufficient shear strength after a short curing time, avoiding the instability of adjacent previously built panels.

Therefore, much progress has been made in developing both the efficiency prediction and the installation technique of medium depth to deep longitudinal drainage trench systems. Such progress makes the mitigation of deep landslide activity through such measure more sustainable, given the lower cost and the longer life of drainage trenches. The drainage effects can be nowadays predicted more accurately and controlled through the monitoring of the indicators of the landslide activity, such as the pore water pressures. 
a)

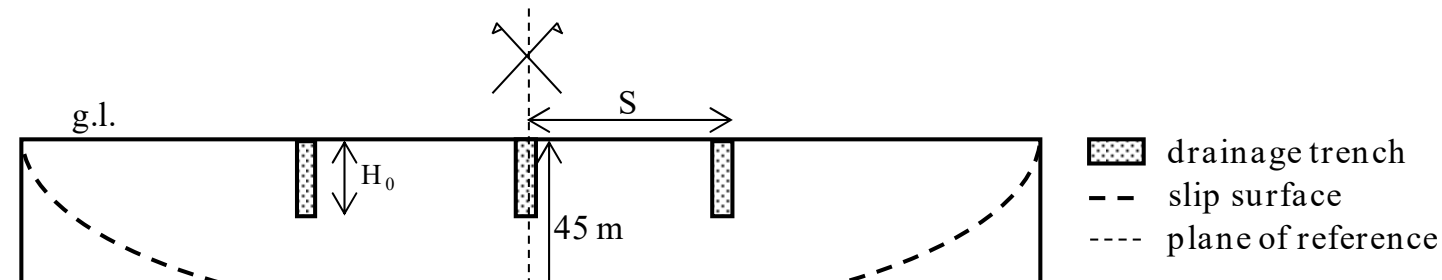

b)

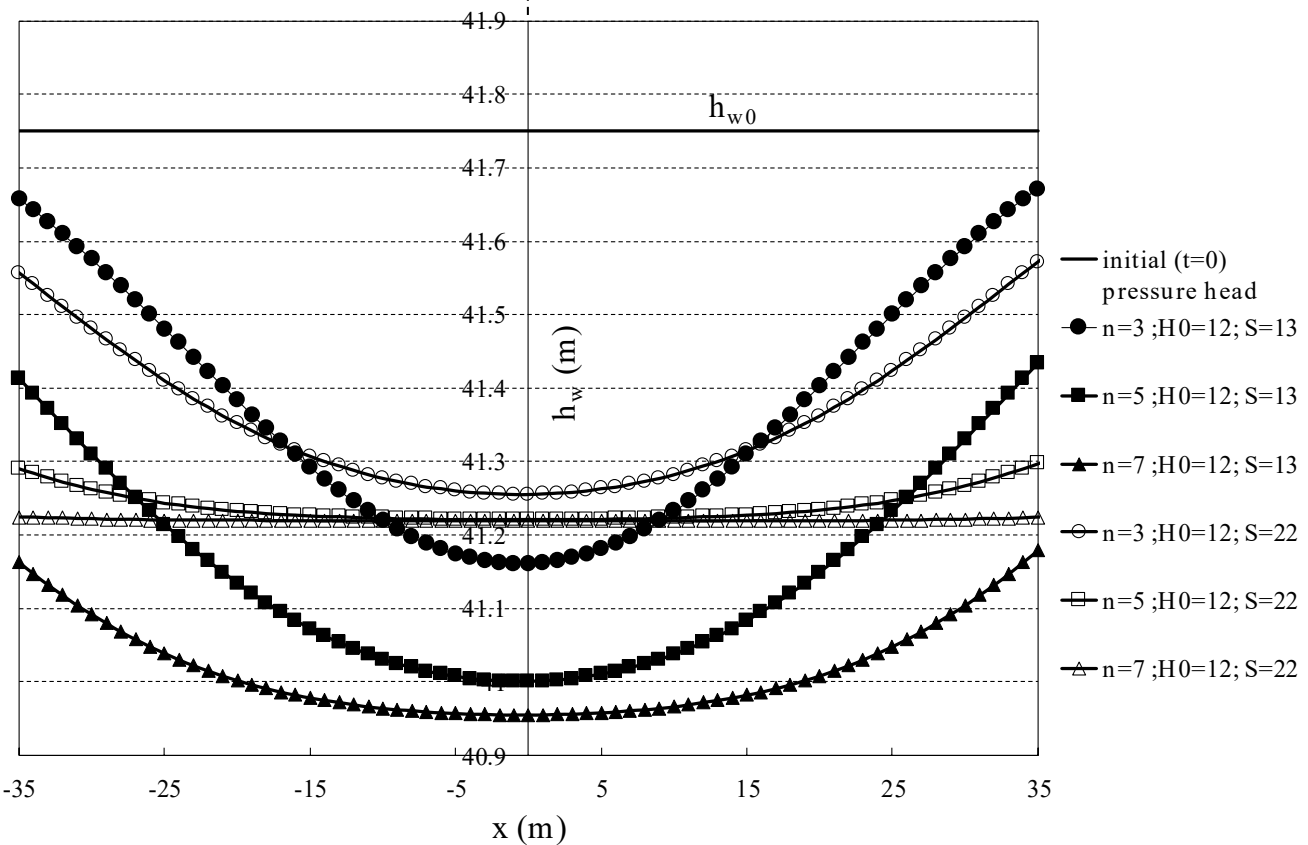

Figure 4. (a) Scheme of a prototype drainage trench system and (b) pressure heads for different trench systems (see legend), along a horizontal plane at depth $\mathrm{z}=45 \mathrm{~m}$ below g.l. (see plane of reference in panel (a)), at the start of the seepage analysis $\left(\mathrm{h}_{\mathrm{w} 0}\right)$ and after 5 years of transient seepage since the installation of the system (revisited from work in [11]).

The aim of the present paper is to provide a methodology for an innovative design of systems of longitudinal medium depth drainage trenches, showing that these can allow for pore water pressure reductions at depth, relevant to the slope stabilization. In particular, through 2D finite element analyses in the transversal slope section (e.g., Figure 4), the study is aimed at exploring the variation of the hydraulic efficiency, E, on deep sliding surfaces, with the change in the geometric and hydraulic parameters of the trench system. From the analysis results, the assessment of the increase of the slope stability factor, $\mathrm{F}$, is derived. As the research work is framed in a larger study about the mitigation measures most sustainable in a pilot region, the Daunia Apennines (Southern Italy), the results will make reference to the slope features in such region. Nevertheless, the results are deemed to be extended to contexts of similar geo-hydro-mechanical features to those of the Daunia Apennines.

\section{The Deep Landsliding of Reference in the Study}

The Daunia Apennines (Figure 5) are located in the eastern sector of the southern Italian Apennines. Here, clayey slopes have been involved in intense tectonic processes, so that the clays are often intensely fissured and characterized by rather low strength parameters, with fractured rocks floating in the clay matrix. Furthermore, deep slow historical landslides recur in such slopes, whose activity is often connected to the slope-atmosphere interaction [10,22-25]. 


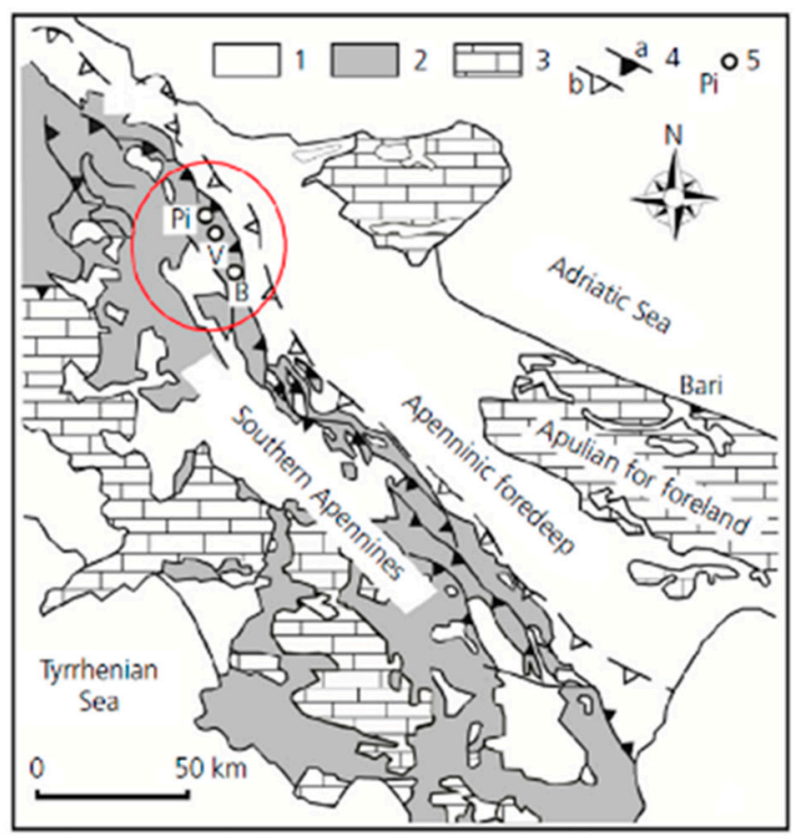

Figure 5. Schematic geological map of the Southern Apennines and location of the study region (included in the ellipse). Key: 1-marine and continental deposits, wedge basin deposits, 2-Apenninic units, 3-carbonate platform units, 4-main thrust (a) and buried overthrusting (b), 5-case studies: B-Bovino, Pi-Pietramontecorvino, V-Volturino (from work in [11]).

In particular, Cotecchia et al. [26] recognized three recurrent geo-hydro-mechanical set-ups in the region, named GM1, GM2, and GM3 (Figure 6), characterized by the alternation of rock layers and clay layers. These set-ups differ mainly for the trend of the contact between the rock layer and clay layer. Furthermore, based on extensive field surveys and monitoring, Cotecchia et al. [26] recognized four main classes of landslide mechanism in the region: class M1 (Figure 6) includes compound slides, usually deeper than $30 \mathrm{~m}$, whose length is comparable with the width; Class M2 (Figure 6) corresponds to mudslides that can have one or more source areas and whose body can be either elongate or lobate; class M3 (Figure 6) includes the most complex landslides, such as shallow earth sliding-flows or flow-slides [27]; and finally, M4 (Figure 6) is represented by deep rotational landslides evolving into an earth-flow downslope. Inclinometer monitoring has given evidence to the evolution with time of the sliding rates of several bodies, of either M1 or M2 type (Figure 6), with slip surfaces reaching 30 to $50 \mathrm{~m}$ maximum depth. Moreover, the piezometric monitoring has given evidence to concurrence of a slow rise in piezometric head (from the end of August to late winter/early spring) and the increase in sliding rate of the cited landslide bodies. At the stage of maximum piezometric head, the landslide rates reach maximum values [10], showing that the seasonal piezometric rise causes acceleration of landsliding.

Cotecchia et al. [22,28] have demonstrated, based on both the above cited field data (Figure 7) and numerical modeling, that the quoted relation between the piezometric head rise and the sliding acceleration is consequent to the seasonal infiltration in the slopes of the region of the net rainfalls, equal to the difference between the total rainfalls, the runoff, and the evapotranspiration rates triggered by the regional climate. The infiltration in the fissured clay slopes generates, over the year, seasonal fluctuations of the pore water pressures down to large depth, given the hydraulic properties (water retention curve and permeability function) of the clayey soils forming the flysches. The excursions in the available shear strength consequent to the pore water pressure variations, result in accelerations and decelerations of pre-existing landslide bodies (Figure 7). As can be observed at the two pilot sites, Volturino and Pisciolo (Figure 7a,b), representative of several other hillslopes in the region and where monitoring was carried out (Figure 5), the maximum piezometric heads concur with both the maximum values of the long term cumulative rainfalls (90 to 180 days), and the maximum deep displacement rates. The latter are measured in correspondence of the shear bands intercepted by 
the inclinometers, at the end of winter (Figure 7). At Pisciolo, the maximum displacement rate of the landslide body at the end of winter, detected through inclinometric monitoring, is also confirmed by means of GPS monitoring (sensor S2 in Figure 7b).

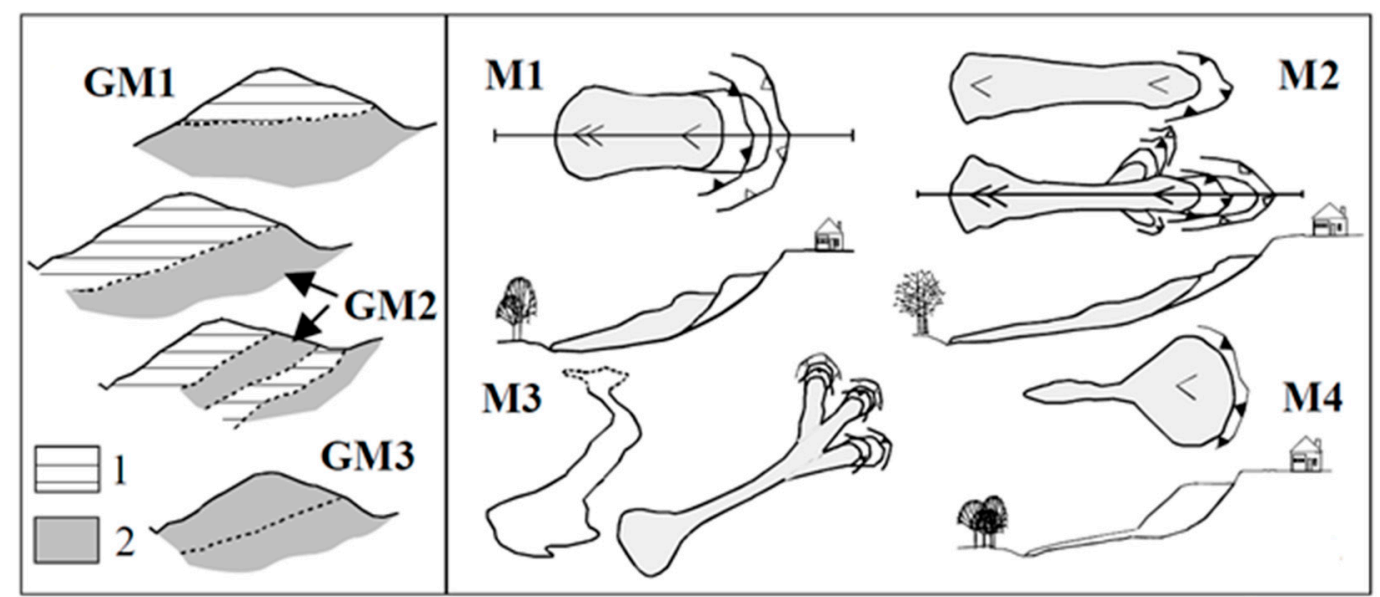

Figure 6. Geomechanical set-ups (GMi) and landslide mechanisms (Mi), typical of Daunia Apennines; key: (1) rock and (2) soil class materials (from work in [26]).

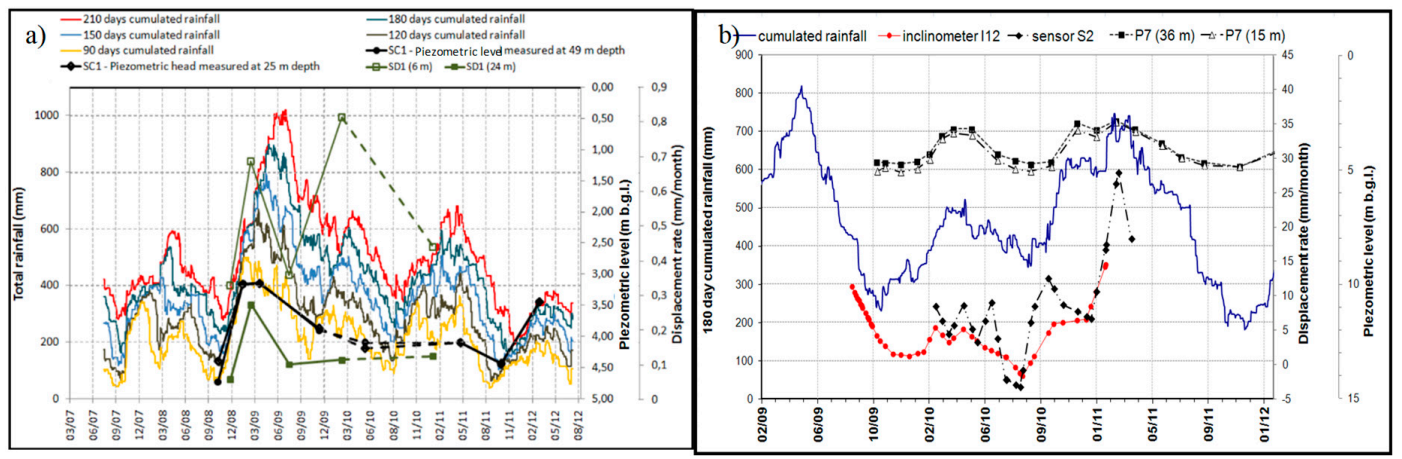

Figure 7. Fontana Monte slope (Volturino) (a): cumulative rainfalls; piezometric levels along SC1; displacement rates measured at $6 \mathrm{~m}$ and $24 \mathrm{~m}$ depth through inclinometer SD1 (from [29]). Pisciolo slope (b): displacement rates measured through the GPS sensor S2 and the inclinometer I12, at $19 \mathrm{~m}$ depth; piezometric levels along P7; 180 days cumulative rainfalls (from work in [22]).

Given the diagnosis of the deep landslide mechanisms discussed so far [10], the adoption of drainage measures to reduce the high piezometric heads in the slopes represents a rational strategy to mitigate the landsliding. In particular, following the earlier work from Cotecchia et al. [11] and accounting for the geometric features of the landslide bodies in the region, a system of longitudinal medium depth drainage trenches (Figure 4a), of depth $\mathrm{H}_{0}$ ranging between 12 and $22 \mathrm{~m}$, is here proposed as a landslide mitigation technique, that conjugates mitigation efficacy, durability and sustainability. As field studies have led to recognize for most of the landslides in the pilot region a "bowl-shaped" slip surface, of the type sketched in Figure 4a, the study aims at providing indications about the design of the drainage trenches to reduce the pore water pressures on a slip surface of such type. In the following, the results of finite element analyses of the transient seepage induced by the installation of systems of drainage trenches of different geometric and hydraulic parameters are discussed. The Fontana Monte landslide at Volturino has been selected as prototype landslide in the assessment of the stabilization efficacy of the deep drainage trench systems, discussed in the following (Figure 8 [30]). It is a M2 type active landslide, lying in a slope formed of fissured stiff clays, the Toppo Capuana clays, alternating with fractured rock layers. In the following, the analysis of the seepage through the slope after the installation of various drainage trench systems is presented. 
By comparing the piezometric heads post-installation " $\mathrm{h}_{\mathrm{w}}$ " (after 5 years since the trench system setting up, see Figure $8 b$ ) and the initial piezometric heads, " $\mathrm{h}_{\mathrm{w} 0}$ ", the efficiency $\mathrm{E}(\mathrm{t})$ of the trench system across the slope is discussed. Thereafter, the effects of the piezometric head reduction generated by the trench system, on the stability factor F of the Fontana Monte landslide (Figure 8b) are examined. As first, in the following, the calculation strategy of both $\mathrm{E}(\mathrm{t})$ and of the stability factor $\mathrm{F}$, is presented.
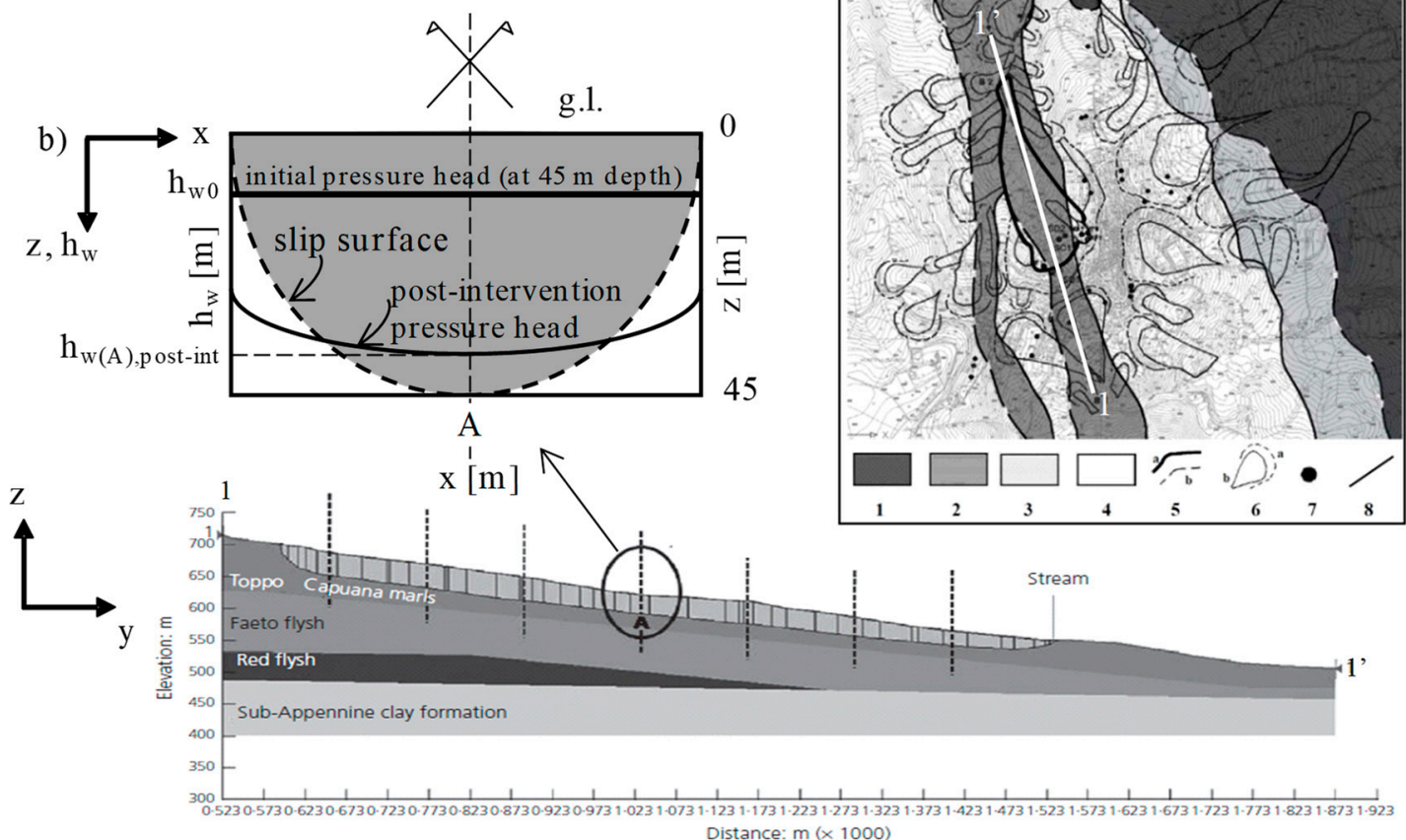

Figure 8. (a) Geomorphological map of the Fontana Monte (Volturino) unstable slope (revisited from work in [11]). Key: (1) sub-Apennine clay, (2) Toppo Capuana clay, (3) Red Flysch, (4) Faeto Flysch, (5) geological contact, (6) landslide, (7) piezometric and/or inclinometric survey, (8) trace of the section in panel (b). Longitudinal section and zoom of transversal section ((b), revisited from work in [11]) of the slip surface with the pressure head distributions on a horizontal plane at $45 \mathrm{~m}$ depth.

\section{Calculation Strategy}

The effect on the landslide body stability factor, $\mathrm{F}$, of the installation of a drainage trench system has been derived through numerical calculations, following the procedure discussed hereafter, referring to the calculation model sketched in Figure 9. As first, transient seepage analyses have been carried out, in two dimensions (2D), within the transversal section of the slope model, including the drainage trench system, shown in Figure 9b. In the slope model in Figure 9, the plane seepage in the transversal section is assumed to be the same in all the transversal sections: a, b, c, and d. Therefore, the piezometric heads, both before and after the installation of the trenches, have been calculated with reference to a single transversal section (Figure $9 \mathrm{~b}$ ). The seepage analysis in such section has been carried out following the same procedure presented by Cotecchia et al. [11]. According to such procedure, for each set of geometric parameters of the trench system (number of trenches $n$, depth of the trenches $\mathrm{H}_{0}$, distance between the trenches $S$ ), the value of the piezometric head reduction after 5 years since the installation of the system has been determined across the whole section. Therefore, from such seepage analysis, the piezometric head reductions along the slip surface shown in Figure 9c could be derived. Thereafter, the safety factor of the landslide body has been evaluated through the limit equilibrium method for three longitudinal sections: $1-1^{\prime}, 2-2^{\prime}$, and 3-3' in Figure 9. In the prototype transversal section (Figure $9 \mathrm{~b}$ ), section $2-2^{\prime}$ and section $3-3^{\prime}$ are located at $48 \mathrm{~m}$ and $96 \mathrm{~m}$ from the central axis (i.e., from section $\left.1-1^{\prime}\right)$, respectively. 


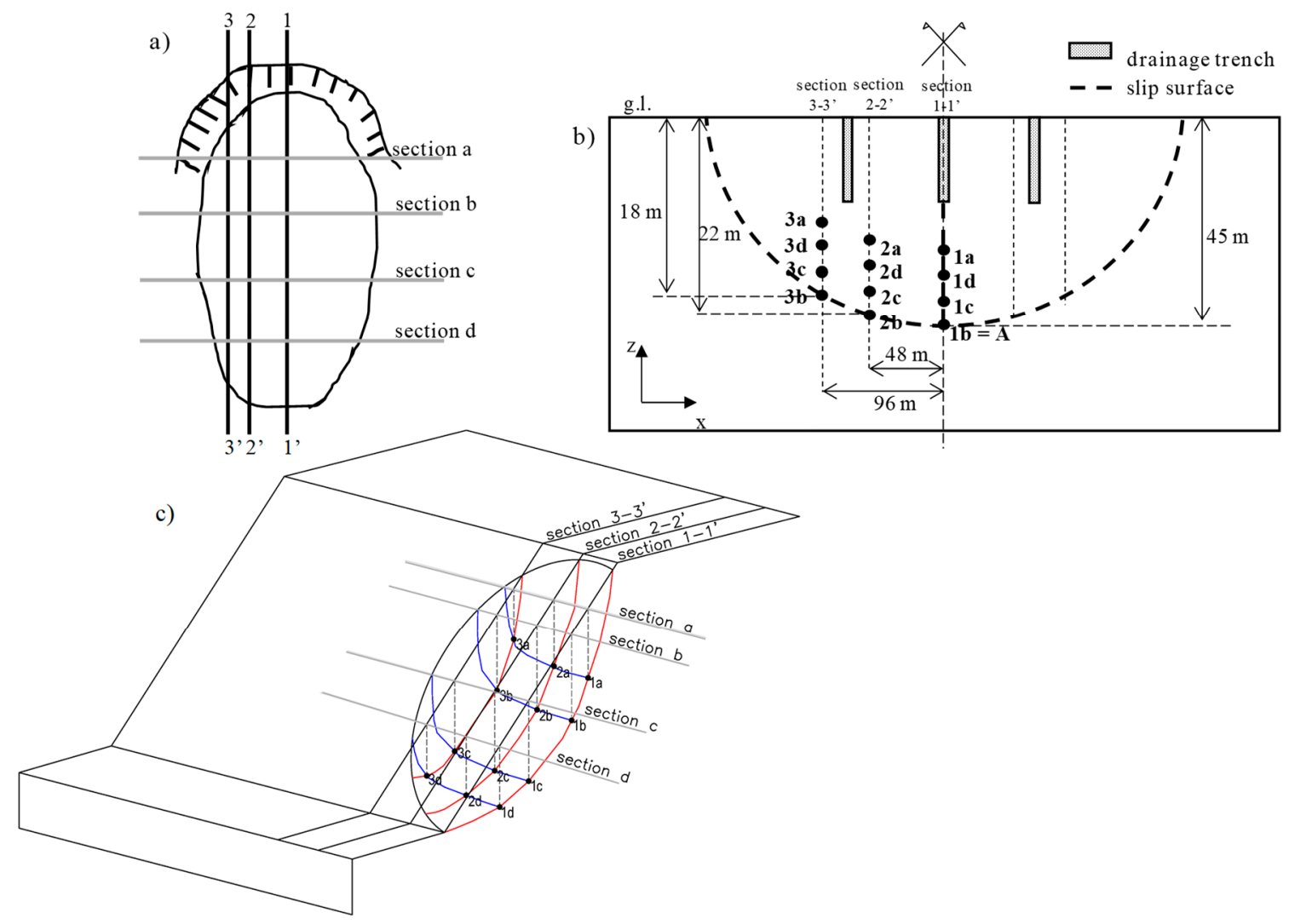

Figure 9. Scheme of reference in the calculation: map of the landslide body (a); sketch of the transversal section, with the traces of the longitudinal sections and the piezometric head calculation points of reference in the $2 \mathrm{D}$ stability analyses (sections $1-1^{\prime}, 2-2^{\prime}$ and $3-3^{\prime}$ in (a)) (b); axonometry of the bowl-shaped slip surface (c) and of the piezometric head calculation points.

To such aim, for section 1-1' , the piezometric head reduction at points $1 \mathrm{a}, 1 \mathrm{~b}, 1 \mathrm{c}$, and $1 \mathrm{~d}$ in Figure $9 \mathrm{c}$ were derived from the seepage analysis at the corresponding points in the transversal section shown in Figure $9 \mathrm{~b}$. The piezometric heads along the longitudinal section between these four points have been assumed to vary linearly. The same procedure was used also for both sections $2-2^{\prime}$ and 3-3'.

In the following, the pore water pressure reductions generated by the trench system are presented in terms of the hydraulic efficiency $E(t)=\left[1-h_{w}(t) / h_{w 0}\right][16,31]$, where $h_{w}(t)$ is the pressure head varying with consolidation after the trench installation at time $t, h_{w 0}$ is the initial pressure head, and $\overline{\mathrm{E}}(\mathrm{t})$ is the average value over a horizontal segment of $15 \mathrm{~m}$ including the numerical point. In particular, in the following the discussion will focus on the $\bar{E}(t)$ values calculated for point $A$ (Figure $9 b$ ), with reference to different trench systems. Point A (i.e., point $1 b$ in Figure 9c), represents the deepest point of the slip surface, at $\mathrm{z}=45 \mathrm{~m}$ depth, therefore the point where the piezometric head reduction is minimum. Therefore, the $\mathrm{E}(\mathrm{t})$ in $\mathrm{A}$ is the minimum possible on the slip surface (Figure 9c). The safety factors for the longitudinal sections $1-1^{\prime}, 2-2^{\prime}$, and 3-3', were derived using the limit equilibrium method [32]; in particular, the morphology and the geotechnical parameters of the Fontana Monte landslide body were accounted for in such analyses (Figure 8), as discussed later in the paper. The increase in safety factor, $\mathrm{F}$, is discussed for different trench systems.

It is worth clarifying that the use of the here explained approach to the assessment of the slope stability, both before and after the intervention, is rather simple (e.g., it disregards a probabilistic analysis), because the values of the stability factor for the three sections represent just a mean for comparison of the increment of the degree of stability of the landslide body, achieved with the trench system installation. 


\section{Analysis of the Transversal Seepage Determined by the Drainage Trench System}

$\overline{\mathrm{E}}(\mathrm{t})$ has been calculated at any point of the transversal section, through 2D seepage analyses (Figure 9b), for five after the activation of the drainage trenches. It is assumed to coincide with the $\overline{\mathrm{E}}(\mathrm{t})$ in the slope, assuming that the influence on $\overline{\mathrm{E}}(\mathrm{t})$ on the component of the flow rate normal to the transversal section can be disregarded, according to Stanic [13] and as done previously in a similar calculation by Cotecchia et al. [11].

The numerical FE modeling of the seepage in the transversal section (Figure $9 b$ ) was carried out with reference to the mesh shown in Figure 10. In the numerical model, the trenches have been simulated as rectangular clusters of $1 \mathrm{~m}$ width, filled with a coarse-grained soil of low retention capacity (Figure 11).

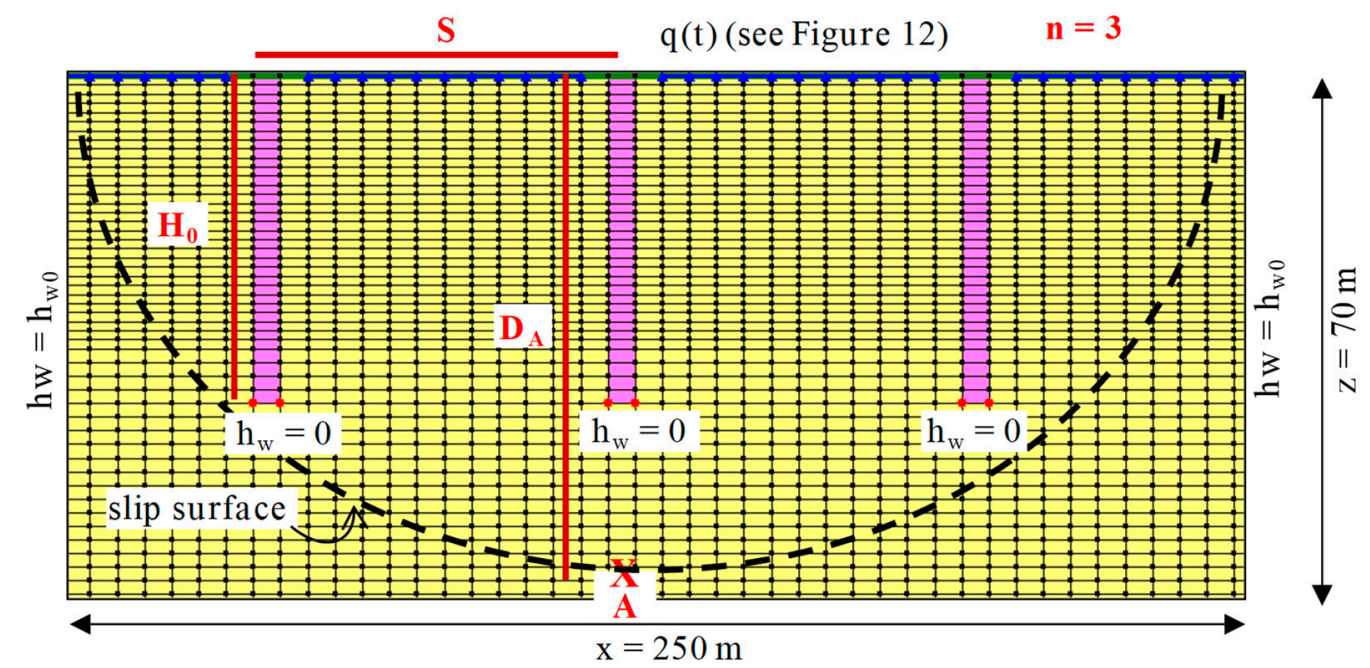

Figure 10. Schematic cross section of the landslide body and drainage trenches (modified from work in [11]).

In Figure 10, a prototype system is shown, made of three trenches $(n=3)$; the mesh is coarser at the bottom of the model and finer in the upper part, discretized by means of 18000, 4-noded quadrilateral elements, with four Gauss points, and 18,281 nodes. The drainage in each trench has been guaranteed by setting zero pore water pressure at the base level of the trench and applying the water retention function and the permeability function of a coarse soil filling the trench.

The section of a slip surface with the seepage plane is also shown in Figure 10, where point A represents the deepest point of the slip surface (see also point $1 \mathrm{~b}$ in Figure 9c).

In the 2D FE seepage model, the ground surface is assumed to be horizontal and the hydraulic properties of the slope soil, where the trenches are installed, are set to be uniform. The numerical modeling has been carried out by means of the finite element code Seep/w [32] that allows for a full numerical integration of the Richards' equation:

$$
\frac{\delta}{\delta x}\left[\frac{K\left(h_{w}\right)\left(\delta h_{w}\right)}{\delta x}\right]+\frac{\delta}{\delta y}\left[K\left(h_{w}\right)\left(\frac{\delta h_{w}}{\delta y}+1\right)\right]=\frac{\delta \theta\left(h_{w}\right)}{\delta t}
$$

Assuming partially saturated conditions for the soil above the water table. $h_{w}$ is the pore water pressure head, and $\theta=S \mathrm{n}$ is the volumetric water content, where $\mathrm{S}$ is the degree of saturation and $\mathrm{n}$ is the porosity. The modeling has implemented the soil water retention curve (WRC), $\theta(\mathrm{s})$ (where $s$ is the soil suction, equal to $\left.\left(\mathrm{h}_{\mathrm{w}} \gamma_{\mathrm{w}}\right)<0\right)$, and the soil hydraulic conductivity function, $\mathrm{K}(\mathrm{s})$, which has been assumed to be related to $\theta(\mathrm{s})$ according to Mualem [33]. For $\theta(\mathrm{s})$, the adopted WRCs refer to interpolation of laboratory test results, as shown in Figure 11, whereas for K(s), the expression from Mualem-Van Genuchten [34] has been adopted. In particular, the WRC used for the clay was derived from experimental laboratory tests, carried out by Cafaro \& Cotecchia, 2001 [35], on an unfissured 
high retention overconsolidated clay, whereas the WRC of the soil in the trenches has been taken as that typical for gravel [14]. In Figure 11, the WRC of the two soils, clay and gravel, used in the model are compared with the WRC measured for a silty sand by Bottiglieri et al. [36]. For the permeability of the saturated clay, a value representative of the "field clay permeability", which is about $\mathrm{K}_{\mathrm{sat}}=1 \times 10^{-9} \mathrm{~m} / \mathrm{s}$, has been adopted, following what already done with reference to the Fontana Monte slope by Lollino et al. [30] and Cotecchia et al. [11]. Both the high retention capacity and the very low permeability of the clay implemented in the model are to be considered conservative in the assessment of the efficiency of the drainage system [10].

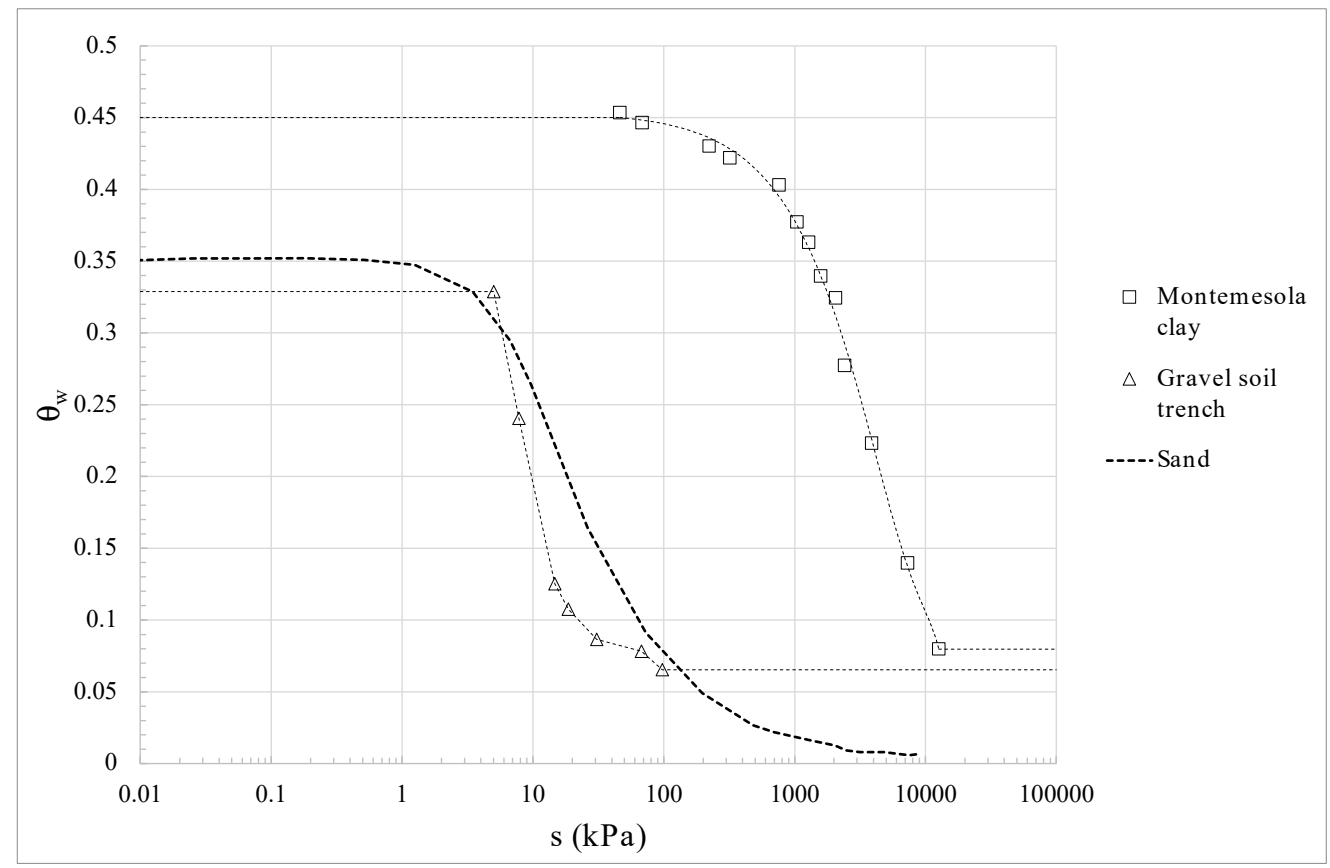

Figure 11. Water retention curves of the Montemesola clay and of the trench filling material (from [11]), compared with a silty sand [36].

Initial hydrostatic conditions with water table at $3 \mathrm{~m}$ depth below g.l., representative of winter conditions, have been set in the analyses [11]. At the lateral boundaries of the model, a constant hydraulic head (hydrostatic condition) has been assigned, $h_{w}=h_{w 0}$, which represents the most conservative boundary condition for the drainage efficiency; the lower boundary has been set as impervious. At the ground level, the boundary condition has been set as a specific flow rate $q(t)$, variable over time according to the rainfall regime of the Fontana Monte slope. Such flow rate has been set constant over each month of the year and equal to the mean value of the monthly rainfall, which has been derived from the database of the monthly rainfalls recorded at the meteorological station of Volturino in the period 1972 to 2009 (Figure 12). Both evapotranspiration and surface runoff have not been accounted for in the seepage analyses [19], so that an overestimated water supply has been assumed.

Figure 4 shows the results of the analyses carried out for trench systems of different $n$, of depth $\mathrm{H}_{0}=12 \mathrm{~m}$ and spacing $\mathrm{S}$ of either $13 \mathrm{~m}$ or $22 \mathrm{~m}$. The figure reports the pressure heads, $h_{\mathrm{w}}$, predicted after 5 years of consolidation along a horizontal plane located at $45 \mathrm{~m}$ depth. The different curves in the figure refer to systems of different $\mathrm{S} / \mathrm{H}_{0}$, but for constant $\mathrm{H}_{0}=12 \mathrm{~m}$. Figure 4 reports also the initial $h_{w 0}$ at $45 \mathrm{~m}$ depth, assumed to be constant as for a hydrostatic initial condition in the section. The "necklace" shape of the $h_{\mathrm{w}}-\mathrm{x}$ curves corresponds to the group effect cited in the introduction and suggests that, at depth, the drainage trench system generates a piezometric head drop that varies with $x$ and is maximum below the center of the trench system, at $x=0$ (point A of Figures 9 and 10). Furthermore, the results show that the piezometric head at large depth is controlled not only by the 
$\mathrm{S} / \mathrm{H}_{0}$ ratio, but also by the global width $\Sigma \mathrm{S}$ of the trench system, and consequently by the number of the trenches $n$. The $h_{w}$ drop, highest below the center of the trench system, suggests that with landslides of bowl-shaped slip surface, centering the trench system with respect to the landslide body longitudinal section optimizes the stabilizing effect of the system, as shown in Figures 9 and 10. In this way, the deepest portion of the sliding surface benefits from the maximum $h_{w}$ drop determined by the drainage system. The $h_{w}$ drop along the lateral portions of the slip surface is higher than in the central portion because these are shallower.

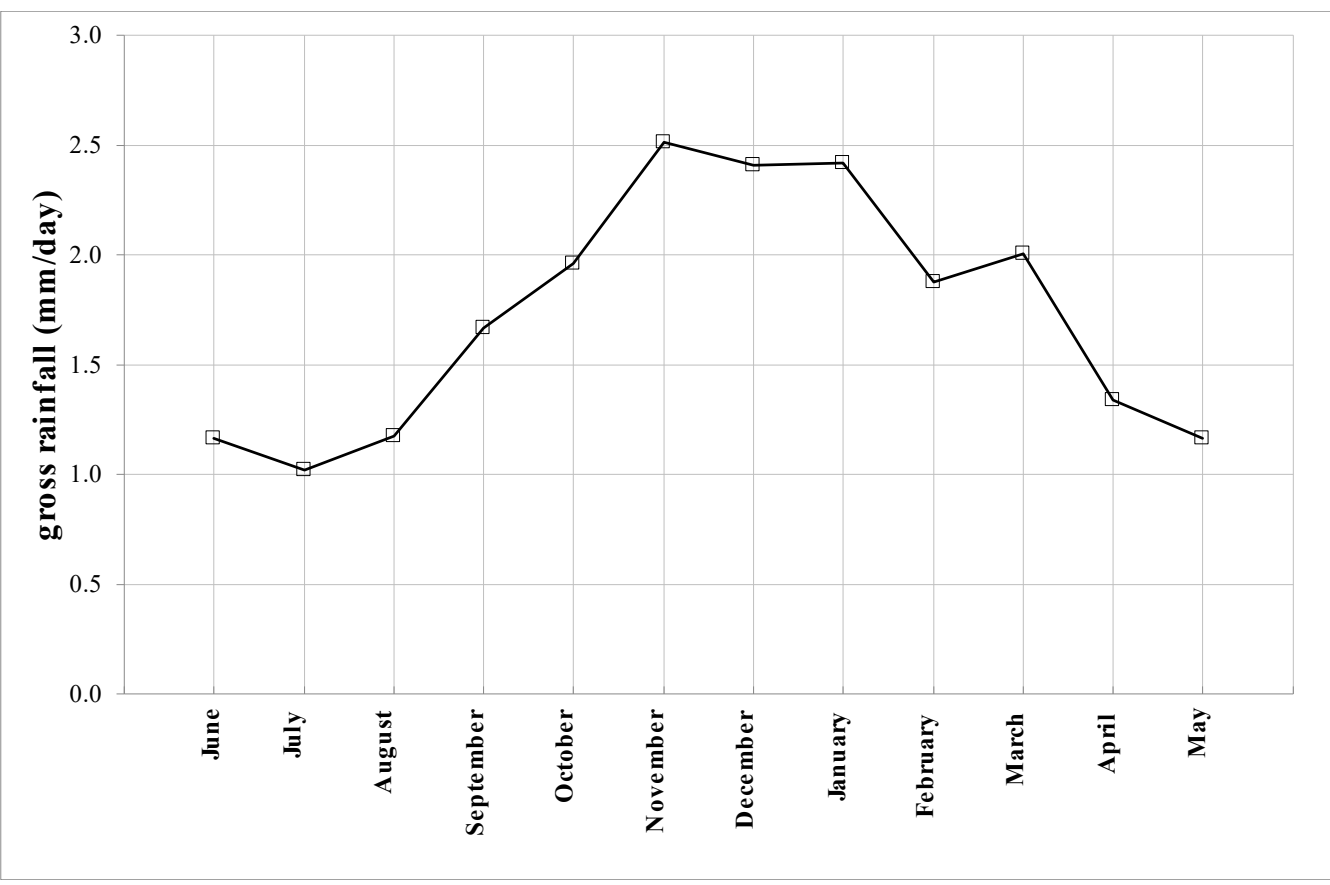

Figure 12. Flow rate values assigned to the upper boundary of the model (from work in [11]).

The $\mathrm{h}_{\mathrm{w}}(\mathrm{x}, \mathrm{z})$ determined by the trench system is the input of the stability analysis, resulting in the stability factor $\mathrm{F}$ :

$$
F=\frac{\int \tau_{f} d s}{\int \tau_{m} d s}=\frac{\int\left(c^{\prime}+(\sigma-u) \tan \varphi^{\prime}\right) d s}{\int \tau_{m} d s}
$$

where $\tau_{\mathrm{f}}$ is the shear strength available on the slip surface; $\tau_{\mathrm{m}}$ is the mobilized shear strength; $\mathrm{c}^{\prime}$ and $\varphi^{\prime}$ are, respectively, the cohesion intercept and the friction angle; $\sigma$ is the total normal stress; and $\mathrm{u}=\gamma_{\mathrm{w}} \mathrm{h}_{\mathrm{w}}$ is the pore water pressure.

\section{Assessment of the Hydraulic Efficiency for Different Trench Systems}

\subsection{Comparison of the New Modeling Results with Background Modeling}

As first, the hydraulic efficiency resulting from the numerical modeling of the seepage in presence of the drainage trenches described before has been compared with the trench system efficiency predicted in previous studies. In particular, the new predictions have been compared with those resulting from the modeling which assumes the soil to be fully saturated also above the water table and the number of trenches, $n$, to be infinite, according to the scheme from Stanic [13], shown in Figure 3. In this way, the effects on $\bar{E}$ of implementing more realistic seepage conditions in the modeling, such as a finite number of trenches, which provide a group effect, and partially saturated conditions which control the water mass balance in the top layers, can be verified. 
To this aim, the $\overline{\mathrm{E}}$ values achieved through the new modeling (Figure 10) have been compared with those reported by Desideri et al. [16] for steady-state conditions, in Figure 13, whose notation is the same as that shown in Figure 3a. The new seepage calculations implemented the same boundary conditions at the ground surface used by Desideri et al. [16], i.e., the presence of a permanent film of water at $\mathrm{u}=0$, and an initial water table at the ground level, i.e., $\mathrm{h}_{\mathrm{w} 0}=\mathrm{D}$ (Figure 10). The results plotted in Figure 13 refer to different depths $\mathrm{D}: \mathrm{H}_{0}, 1.5 \mathrm{H}_{0}$, and $2 \mathrm{H}_{0}$ for both models. In particular, it must be highlighted that in the figure $\overline{\mathrm{E}}$ is the average over a distance equal to $S$ (Figure 10); for the new modeling, $\overline{\mathrm{E}}$ has been averaged over a horizontal segment $\mathrm{S}$, of depth $\mathrm{D}$, below the center of the trench system. The comparison seems to suggest that accounting for more realistic conditions in the modeling results in a higher $\overline{\mathrm{E}}$ value for $\mathrm{D} / \mathrm{H}_{0}=1$, whereas this is not the case for $\overline{\mathrm{E}}$ at depths larger than $\mathrm{H}_{0}$. Furthermore, the results make evident that $\overline{\mathrm{E}}$ does not depend only on $\mathrm{S} / \mathrm{H}_{0}$; rather, the dependency of $\overline{\mathrm{E}}$ on the trench system geometry, $\mathrm{S}, \mathrm{H}_{0}, \mathrm{n}$, is more complex.

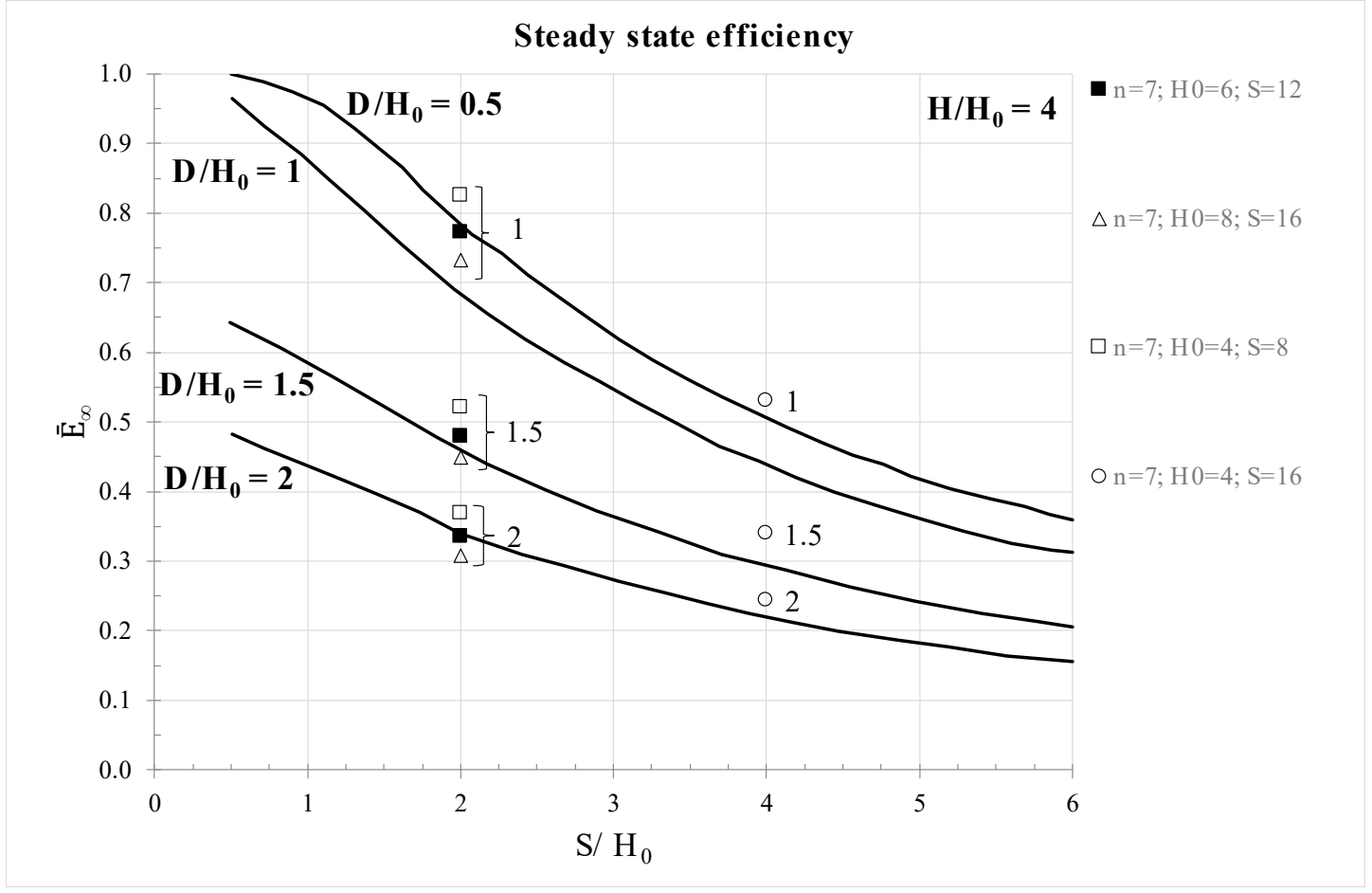

Figure 13. Comparison between data from Desideri et al. [16] and new numerical results.

Di Maio et al. [17], reported results of 2D transient seepage analyses, complying with the same geometric and hydraulic calculation scheme in Figure $3 \mathrm{a}$, for $\mathrm{D} / \mathrm{H}_{0}=1$ (initial water table at ground level), and when two different boundary conditions are implemented at the top of the model: impervious boundary (Figure 14a), or permanent film of water (Figure 14b). In both cases, the efficiency values are plotted with respect to a normalized time $T$, which varies linearly with the saturated coefficient of permeability, the soil elastic stiffness moduli, and time [17]. Figure 14a,b reports also the results of the new modeling (Figure 10) for two drainage trench systems, both of $\mathrm{S} / \mathrm{H}_{0}=2$, still assuming the initial water table at the ground level. The comparison shows that for impervious top boundary (Figure 14a), the new model predicts $\bar{E}$ values smaller than those previously expected, but this is not the case when water is available at the ground surface (Figure 14b), that is a more cautious design condition. 
a)

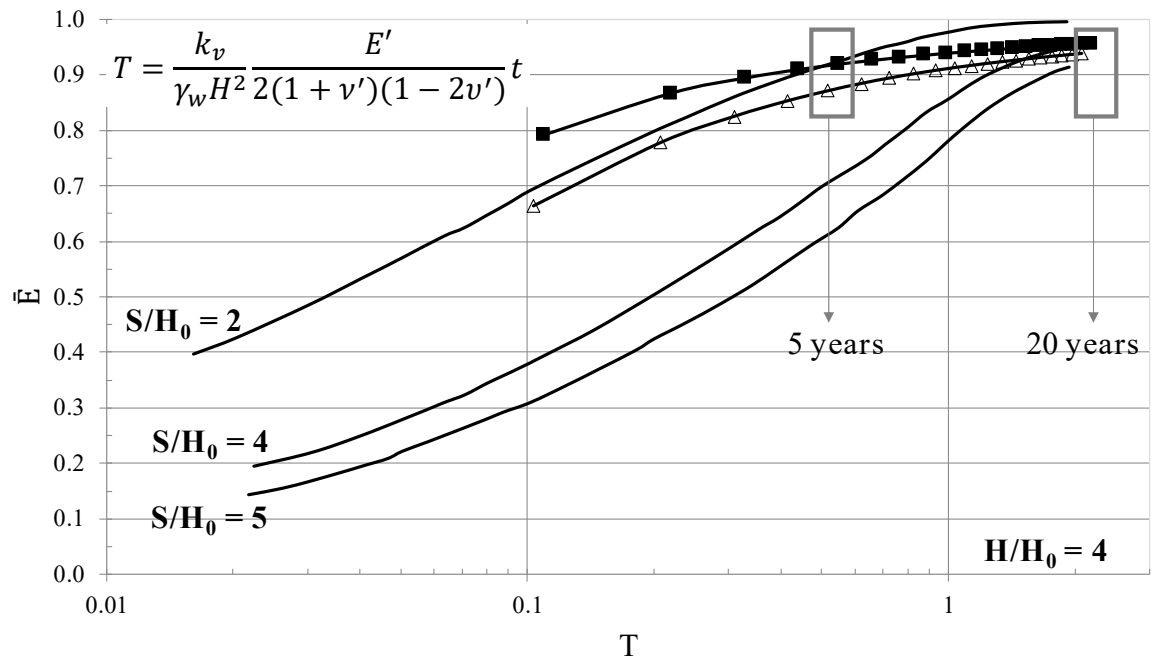

$\rightarrow \mathrm{n}=7 ; \mathrm{H} 0=6 ; \mathrm{S}=12 \quad \rightarrow \mathrm{n}=7 ; \mathrm{H} 0=8 ; \mathrm{S}=16$

b)

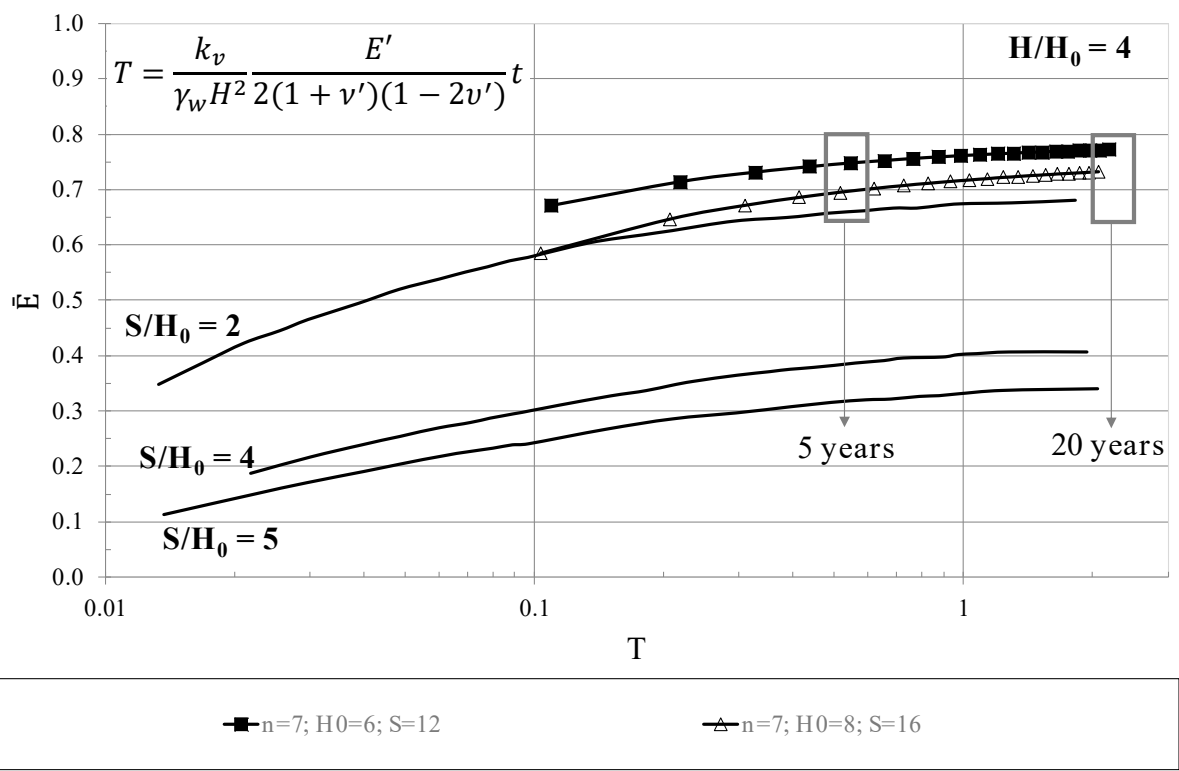

Figure 14. Comparison between data from Di Maio et al. [17] and new numerical results: (a) top impervious boundary; (b) permanent film of water at the top boundary. Indication of 5 years and 20 years refer only to the new numerical analyses.

\subsection{Hydraulic Efficiency at Depth for Different Trench Systems}

Seepage analyses were carried out for different trench systems, varying $n, S, H_{0}$, in order to highlight the influence of each of these parameters on $\bar{E}(t)$.

In detail, the parameters have been set to vary as follows; the trench spacing, $\mathrm{S}$, from $12 \mathrm{~m}$ to $22 \mathrm{~m}$; the trench depth, $\mathrm{H}_{0}$, from $4 \mathrm{~m}$ to $22 \mathrm{~m}$; the corresponding $\mathrm{S} / \mathrm{H}_{0}$ ratio, from 0.75 to 3; the number of trenches, $\mathrm{n}$, from 3 to 7 . Table 1 reports the combination of parameter's values input in the different analyses of reference in the following discussion. 
Table 1. Numerical testing program.

\begin{tabular}{|c|c|c|c|c|c|c|c|c|c|c|c|c|c|c|}
\hline \multicolumn{5}{|c|}{$\mathrm{n}=3$} & \multicolumn{5}{|c|}{$\mathrm{n}=5$} & \multicolumn{5}{|c|}{$\mathrm{n}=7$} \\
\hline$S(m)$ & $\mathbf{H}_{0}(\mathrm{~m})$ & $\mathrm{S} / \mathrm{H}_{0}$ & $\begin{array}{l}\text { Seepage } \\
\text { Analysis }\end{array}$ & $\begin{array}{l}\text { Stability } \\
\text { Analysis }\end{array}$ & $S(m)$ & $\mathrm{H}_{0}(\mathrm{~m})$ & $\mathrm{S} / \mathrm{H}_{0}$ & $\begin{array}{l}\text { Seepage } \\
\text { Analysis }\end{array}$ & $\begin{array}{l}\text { Stability } \\
\text { Analysis }\end{array}$ & $S(m)$ & $\mathbf{H}_{0}(\mathrm{~m})$ & $\mathrm{S} / \mathrm{H}_{0}$ & $\begin{array}{l}\text { Seepage } \\
\text { Analysis }\end{array}$ & $\begin{array}{l}\text { Stability } \\
\text { Analysis }\end{array}$ \\
\hline 12 & 4 & 3 & $\sqrt{ }$ & $\sqrt{ }$ & & & & & & & & & & \\
\hline 12 & 6 & 2 & $\sqrt{ }$ & $\sqrt{ }$ & & & & & & & & & & \\
\hline 12 & 8 & 1.5 & $\sqrt{ }$ & $\sqrt{ }$ & & & & & & & & & & \\
\hline 12 & 10 & 1.2 & $\sqrt{ }$ & $\sqrt{ }$ & & & & & & & & & & \\
\hline 12 & 12 & 1.00 & $\sqrt{ }$ & $\sqrt{ }$ & 12 & 12 & 1.00 & $\sqrt{ }$ & $\sqrt{ }$ & 12 & 12 & 1.00 & $\sqrt{ }$ & $\sqrt{ }$ \\
\hline 12 & 14 & 0.86 & $\sqrt{ }$ & $\sqrt{ }$ & 12 & 14 & 0.86 & $\sqrt{ }$ & $\sqrt{ }$ & 12 & 14 & 0.86 & $\sqrt{ }$ & $\sqrt{ }$ \\
\hline 12 & 16 & 0.75 & $\sqrt{ }$ & $\sqrt{ }$ & 12 & 16 & 0.75 & $\sqrt{ }$ & $\sqrt{ }$ & 12 & 16 & 0.75 & $\sqrt{ }$ & $\sqrt{ }$ \\
\hline 13 & 12 & 1.08 & $\sqrt{ }$ & $\sqrt{ }$ & 13 & 12 & 1.08 & $\sqrt{ }$ & $\sqrt{ }$ & 13 & 12 & 1.08 & $\sqrt{ }$ & $\sqrt{ }$ \\
\hline 14 & 4 & 3.50 & $\sqrt{ }$ & $\sqrt{ }$ & & & & & & & & & & \\
\hline 14 & 6 & 2.33 & $\sqrt{ }$ & $\sqrt{ }$ & & & & & & & & & & \\
\hline 14 & 8 & 1.75 & $\sqrt{ }$ & $\sqrt{ }$ & & & & & & & & & & \\
\hline 14 & 10 & 1.40 & $\sqrt{ }$ & $\sqrt{ }$ & & & & & & & & & & \\
\hline 14 & 12 & 1.17 & $\sqrt{ }$ & $\sqrt{ }$ & & & & & & & & & & \\
\hline 14 & 14 & 1.00 & $\sqrt{ }$ & $\sqrt{ }$ & 14 & 14 & 1.00 & $\sqrt{ }$ & $\sqrt{ }$ & 14 & 14 & 1.00 & $\sqrt{ }$ & $\sqrt{ }$ \\
\hline 14 & 16 & 0.88 & $\sqrt{ }$ & $\sqrt{ }$ & 14 & 16 & 0.88 & $\sqrt{ }$ & $\sqrt{ }$ & 14 & 16 & 0.88 & $\sqrt{ }$ & $\sqrt{ }$ \\
\hline 16 & 12 & 1.33 & $\sqrt{ }$ & $\sqrt{ }$ & & & & & & & & & & \\
\hline 16 & 14 & 1.14 & $\sqrt{ }$ & $\sqrt{ }$ & 16 & 14 & 1.14 & $\sqrt{ }$ & $\sqrt{ }$ & 16 & 14 & 1.14 & $\sqrt{ }$ & $\sqrt{ }$ \\
\hline 16 & 16 & 1.00 & $\sqrt{ }$ & $\sqrt{ }$ & 16 & 16 & 1.00 & $\sqrt{ }$ & $\sqrt{ }$ & 16 & 16 & 1.00 & $\sqrt{ }$ & $\sqrt{ }$ \\
\hline 18 & 12 & 1.50 & $\sqrt{ }$ & $\sqrt{ }$ & & & & & & & & & & \\
\hline 18 & 16 & 1.13 & $\sqrt{ }$ & $\sqrt{ }$ & & & & & & & & & & \\
\hline 22 & 12 & 1.83 & $\sqrt{ }$ & $\sqrt{ }$ & & & & & & & & & & \\
\hline 22 & 14 & 1.57 & $\sqrt{ }$ & $\sqrt{ }$ & & & & & & & & & & \\
\hline 22 & 16 & 1.38 & $\sqrt{ }$ & $\sqrt{ }$ & & & & & & & & & & \\
\hline 22 & 18 & 1.22 & $\sqrt{ }$ & $\sqrt{ }$ & & & & & & & & & $\sqrt{ }$ & $\sqrt{ }$ \\
\hline 22 & 22 & 1.00 & $\sqrt{ }$ & $\sqrt{ }$ & 22 & 12 & 1.83 & $\sqrt{ }$ & $\sqrt{ }$ & 22 & 12 & 1.83 & $\sqrt{ }$ & $\sqrt{ }$ \\
\hline
\end{tabular}


Figure 15 shows the values of the average $\bar{E}(\mathrm{t})$, after 5 years of consolidation, calculated at $45 \mathrm{~m}$ depth, below the center of the trench system (point A in Figure 10), for different $n$ equal either to 3 or to 5 . In the figure, the continuous lines refer to constant $S$ and variable $\mathrm{H}_{0}$, whereas the dashed lines refer to constant $\mathrm{H}_{0}$ and variable $S$; the black lines refer to $n=3$, whereas the gray lines refer to $n=5$. The variability of $\bar{E}$ shown in Figure 15 for $n=3$ is qualitatively representative of the $\bar{E}$ variability found for larger $n$ values, e.g., shown for $n=5$. In particular, for the constant $S$ curves $\bar{E}$ seems to increase exponentially with increasing $\mathrm{H}_{0}$. Conversely, the constant $\mathrm{H}_{0}$ curves show that the maximum $\bar{E}$ corresponds to an optimum $S$ value, and not to the minimum $S$ value. According to the numerical results, then, the trench depth, $\mathrm{H}_{0}$, has a much stronger impact on $\overline{\mathrm{E}}$ than the trench spacing, $\mathrm{S}$. For $\mathrm{n}=3$ and $\mathrm{S} / \mathrm{H}_{0}$ values below 1.5 , reducing $\mathrm{S} / \mathrm{H}_{0}$ of 0.5 provides a much higher increase in $\overline{\mathrm{E}}$ if this is achieved by increasing $\mathrm{H}_{0}$, than if this is reached by reducing $\mathrm{S}$. Moreover, for $\mathrm{S} / \mathrm{H}_{0}$ below 1.2 , even an increase of $\mathrm{H}_{0}$ of $1 \mathrm{~m}$ increases significantly $\overline{\mathrm{E}}$, e.g., for $\mathrm{S} / \mathrm{H}_{0}=0.8, \mathrm{H}_{0}$ from $14 \mathrm{~m}$ to $16 \mathrm{~m}$ increases $\overline{\mathrm{E}}$ from $4 \%$ to $6 \%$.

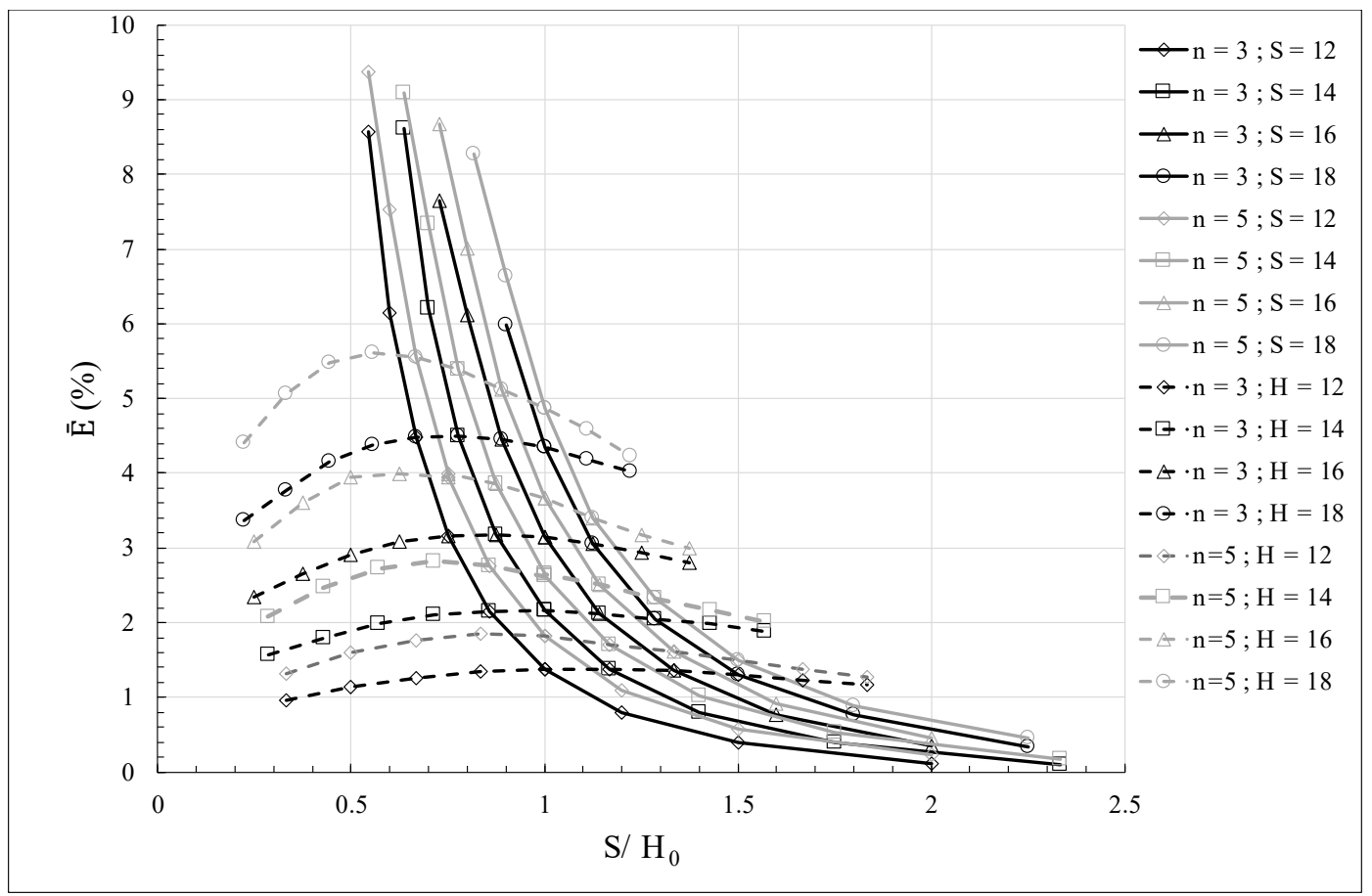

Figure 15. Average efficiency $\overline{\mathrm{E}}(\mathrm{t})$ against $\mathrm{S} / \mathrm{H}_{0}$, for $\mathrm{n}=3$ (black lines) and $\mathrm{n}=5$ (grey lines), at $\mathrm{z}=45$ $\mathrm{m}$ b.g.l $\left(\mathrm{t}=5\right.$ years); dashed lines refer to $\mathrm{S}$ variable and $\mathrm{H}_{0}$ fixed, solid lines refer to $\mathrm{H}_{0}$ variable and $S$ fixed.

For any $\mathrm{S} / \mathrm{H}_{0}$, the $\overline{\mathrm{E}}$ achieved using $\mathrm{n}=5$ is higher than that for $\mathrm{n}=3$. Therefore, given the group effect, the number of trenches impacts the achievable $h_{w}$ drop at very large depth; conversely, $n$ is not a parameter controlling the $\overline{\mathrm{E}}$ at shallow depths achievable through shallow trench systems, as shown in Figure 3, Figure 13, and Figure 14. It comes out that an increase in the number of trenches emphasizes the beneficial effect on $\overline{\mathrm{E}}$ of the increase of $\mathrm{H}_{0}$, more than that due to a reduction in $\mathrm{S}$. All the results in Figures 15 and 16 confirm that $\bar{E}$, at a given depth, is not function of the sole $\mathrm{S} / \mathrm{H}_{0}$.

However, $\overline{\mathrm{E}}$ does not always increase as $\mathrm{n}$ increases, as $\overline{\mathrm{E}}$ decreases for $\mathrm{n}$ increasing beyond a threshold $n$ value. Figure 16 reports the change of $\bar{E}$ as a function of $n$, for a value of $S / \mathrm{H}_{0}$ equal to 1 . An increment about $0.5 \%$ is observed when $n$ increases from $n=3$ to $n=5$, whereas no significant $\bar{E}$ variation is observed from $n=5$ to $n=7$. 


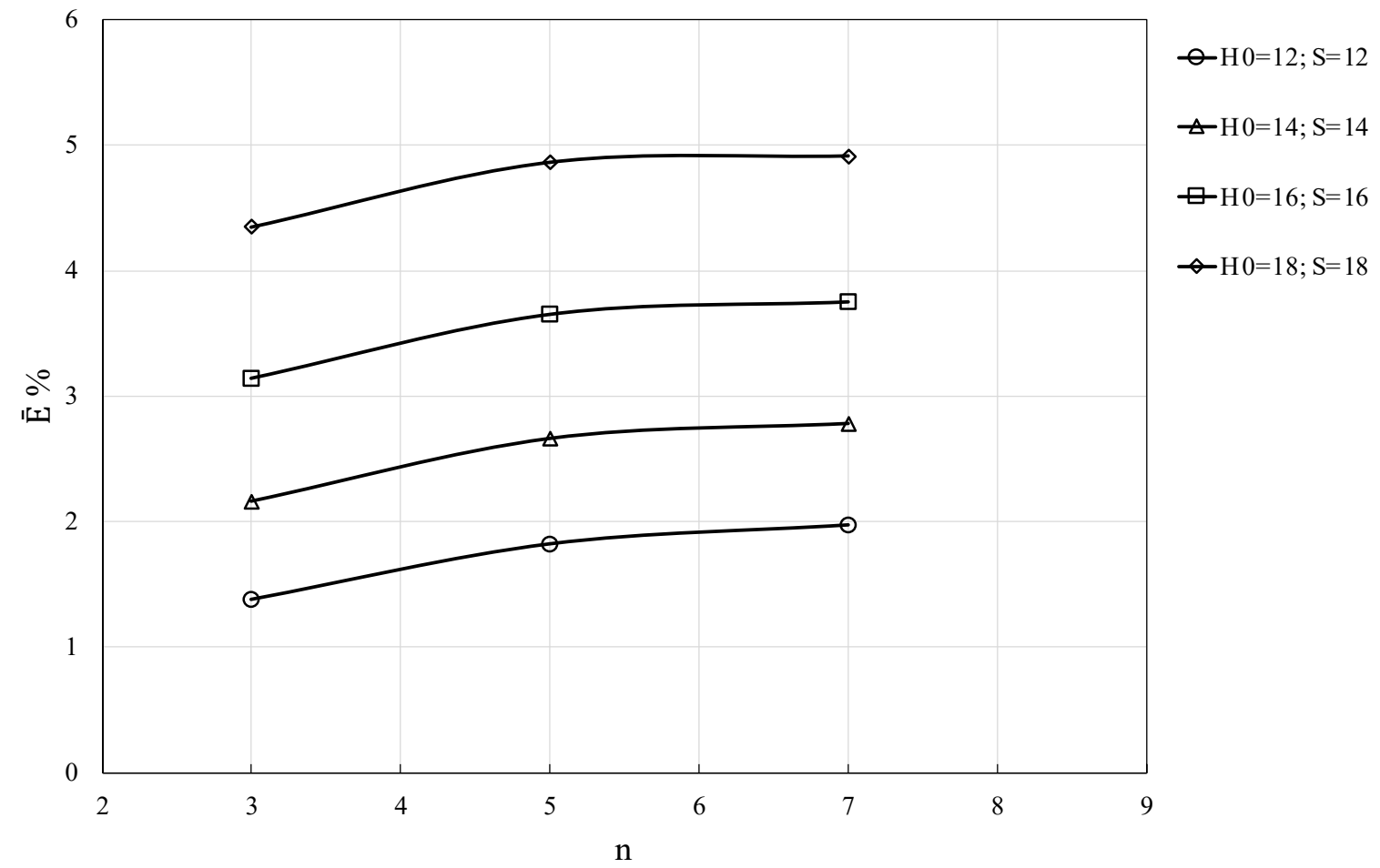

Figure 16. Average efficiency $\bar{E}$ against $n$, at $45 \mathrm{~m}$ depth b.g.l. (point $\mathrm{A}$ in Figure 10 ) and $\mathrm{S} / \mathrm{H}_{0}=1$ ( $\mathrm{t}=5$ years).

Figure 17 shows the whole set of analysis results in terms of $\overline{\mathrm{E}}-\mathrm{H}_{0}$. All the $\overline{\mathrm{E}}-\mathrm{H}_{0}$ curves (each relating to a set n-S of the trench system) fall close to a power function (dotted line in Figure 17), representing the average effect of the drainage trench systems tested through the numerical testing program. Such power function allows estimation of, in first approximation, the $\mathrm{H}_{0}$ value required to reach the desired value of $\overline{\mathrm{E}}$ in the clay slope of reference, by 5 years of transient seepage.

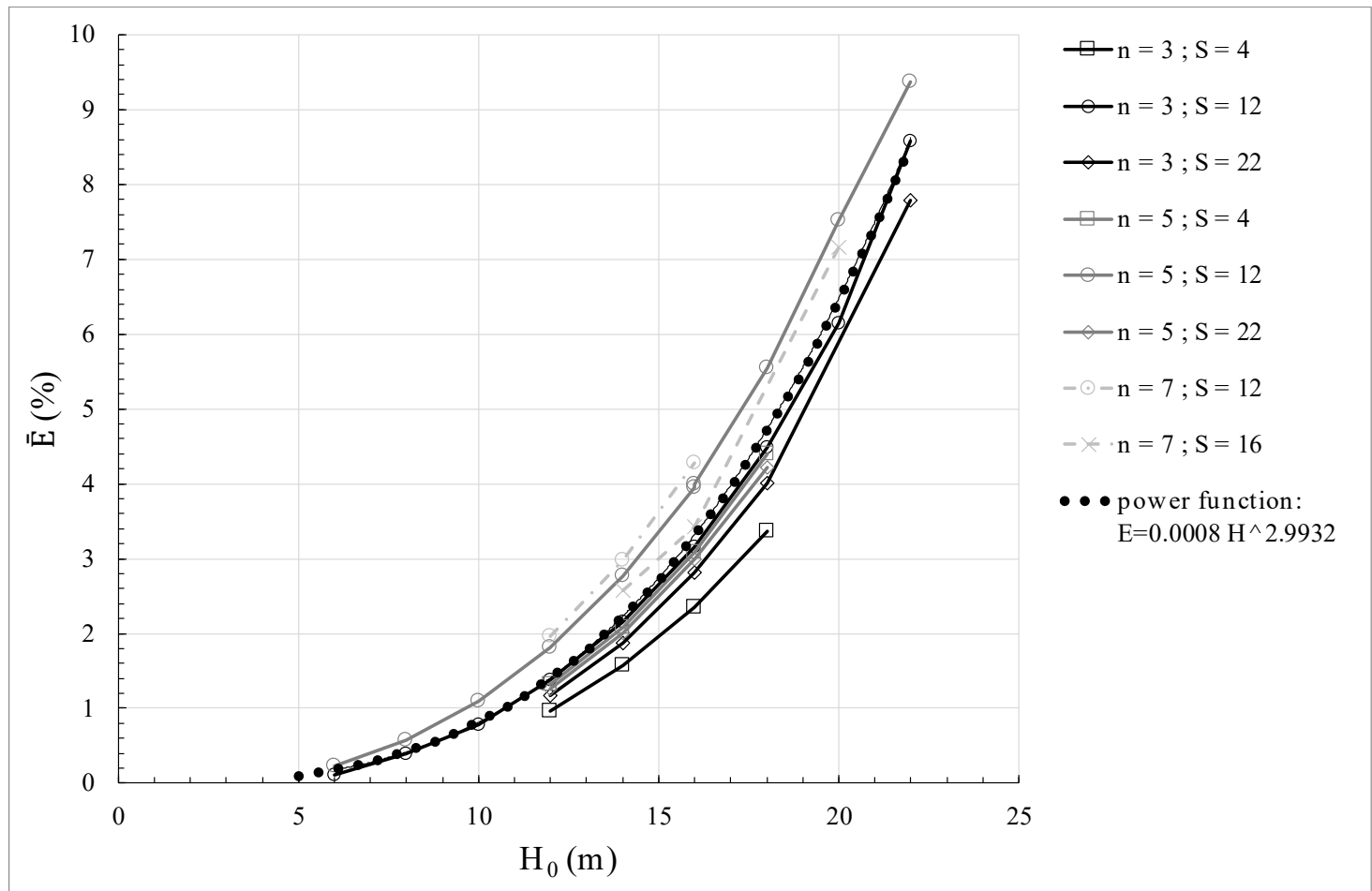

Figure 17. Dependence of the average efficiency, $\overline{\mathrm{E}}$, at $45 \mathrm{~m}$ depth (point $\mathrm{A}$ in Figure 10), on the trench depth, $\mathrm{H}_{0}$, for different trench systems. 
The variation of $\overline{\mathrm{E}}$ with depth has been investigated by comparing the $\overline{\mathrm{E}}$ at $45 \mathrm{~m}$ depth, resulting from all the analyses discussed so far, with $\overline{\mathrm{E}}$ at $25 \mathrm{~m}$ depth, from the same analyses (Table 1). In this way, the hydraulic efficiency pursued through the trench system, when a shallower landslide body has to be stabilized, is examined. The comparison of the drainage efficiency for the two different depth slip surfaces (45 m b.g.l. gray lines; $25 \mathrm{~m}$ b.g.l., black lines, Figure 18), highlights that the efficiency can increase of ten times when passing from a landslide of maximum depth $45 \mathrm{~m}$ to one of maximum depth $25 \mathrm{~m}$.

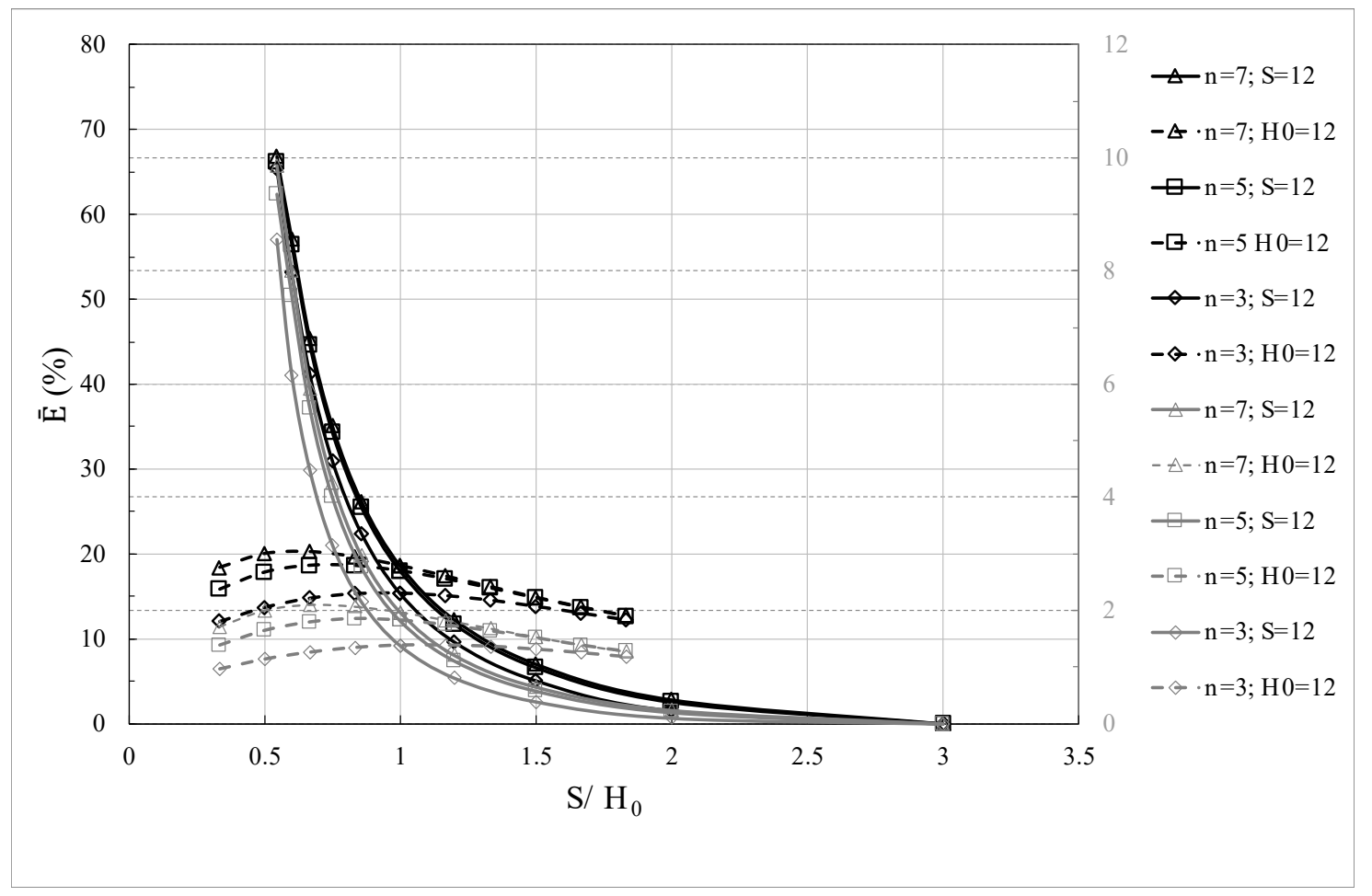

Figure 18. Average efficiency $\overline{\mathrm{E}}$ against $\mathrm{S} / \mathrm{H}_{0}$, when $\mathrm{n}=3, \mathrm{n}=5$ and $\mathrm{n}=7$, at $\mathrm{z}=25 \mathrm{~m}$ b.g.l. (black lines, black vertical axis) and at $\mathrm{z}=45 \mathrm{~m}$ b.g.l. (gray lines, gray vertical axis).

The effect of the soil hydraulic properties on the efficiency of the drainage system has been also investigated. In particular, the saturated coefficient of permeability of the slope soil has been increased from Ksat $=1 \times 10^{-9} \mathrm{~m} / \mathrm{s}$ to Ksat $=3 \times 10^{-9} \mathrm{~m} / \mathrm{s}$. For a drainage trench system characterized by $n=5$, $\mathrm{S}=16 \mathrm{~m}$, and $\mathrm{H}_{0}=14 \mathrm{~m}$, such change of Ksat produces an increase of $\overline{\mathrm{E}}$ from $2.51 \%$ to $7.61 \%$.

\section{Effect of the Drainage Trench System on the Landslide Stability Factor}

The stabilizing effects of the different drainage trench systems are discussed in the following by implementing the results of the seepage analyses, presented above, in 2D limit equilibrium analyses (LE, [32]) according to the procedure discussed in section 3 (Figure 9). Such LE analyses have been performed making reference to the Fontana Monte landslide body [30,37] as prototype landside to be stabilized, adopting the Morgenstern \& Price [38] (code Slope/w [32]). Both the map and one of the sections of the landslide are shown in Figure 19. F has been assumed to be 1 before the installation of the drainage trench system and the mobilized strength parameters $c^{\prime}{ }_{m}-\varphi^{\prime}{ }_{m}$ have been derived, accordingly. $c_{m}^{\prime}$ and $\varphi_{m}^{\prime}$ have been then used in the LE calculation for the section $1-1^{\prime}, 2-2^{\prime}, 3-3^{\prime}$ in Figure 19, to derive $\mathrm{F}$ after 5 years since the trench system installation. Figure $19 \mathrm{~b}$ shows the topography for section $1-1^{\prime}$, along with the slip surface of the landslide body and the piezometric level along the slip surface before the installation of the drainage system. The F post-installation has been calculated for several of the trench systems in Table 1. 
a)

b)
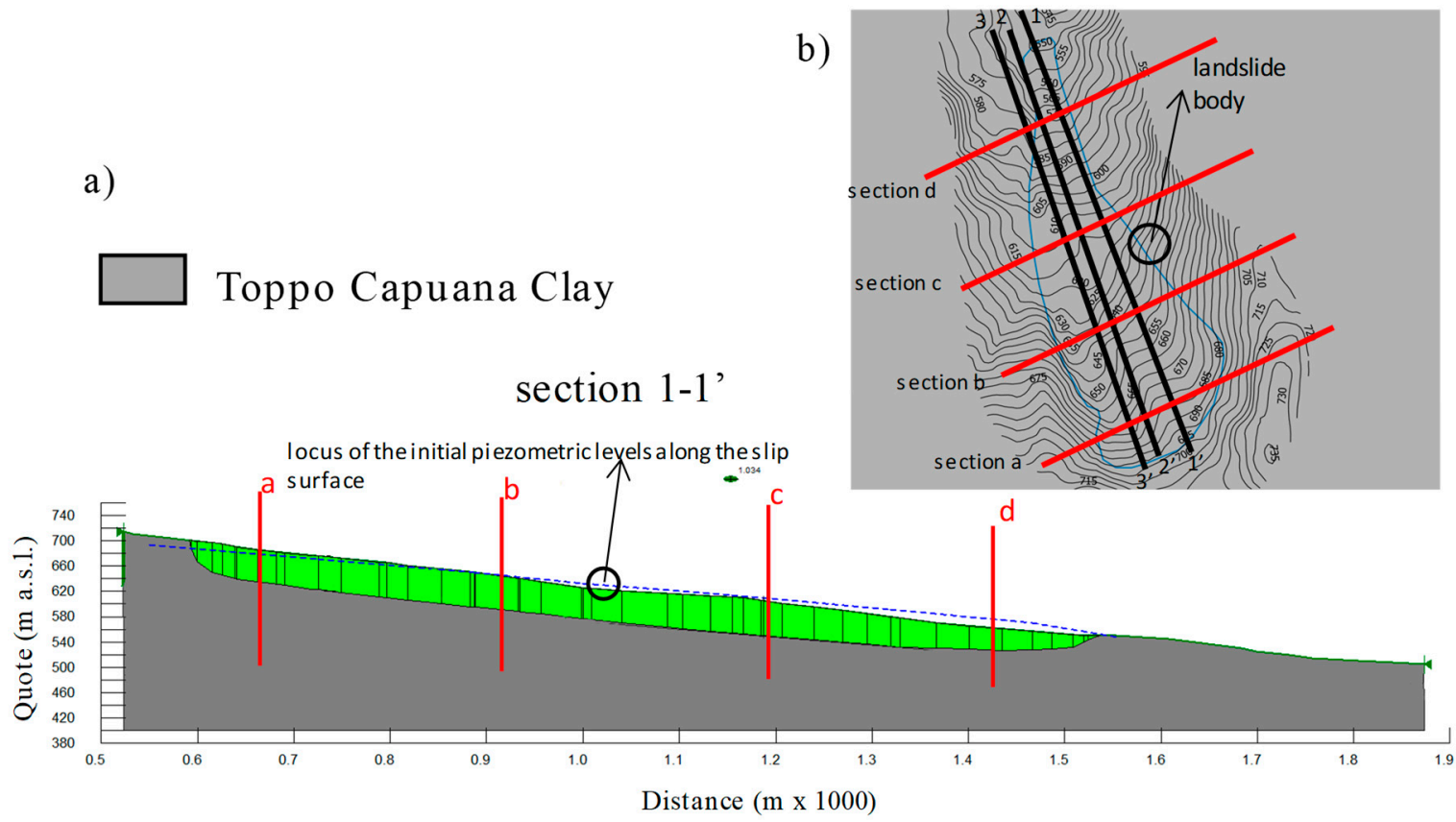

Figure 19. Plan of the Fontana Monte landslide at Volturino, with location of both the longitudinal and the cross sections (a); Longitudinal section 1-1', as implemented in the numerical code (b).

As said before, the slip surface of the Fontana Monte landslide crosses the Toppo Capuana clays, which include a clay fraction ranging between 50 and $70 \%$, are of high plasticity $(30 \%<\mathrm{PI}<80 \%)$ and medium-to-high activity $(0.5<\mathrm{A}<1)$. Due to the fissuring and the high plasticity index of the clay, the values of the peak strength parameters are relatively medium to low, ranging between $\mathrm{c}^{\prime} \mathrm{P}$ $=20 \mathrm{kPa}, \varphi_{\mathrm{P}}^{\prime}=20^{\circ}$. According to the LE back-analyses conducted with reference to section 1-1', implementing the piezometric levels shown in Figure $9 \mathrm{~b}$ [37], the parameter values $\mathrm{c}_{\mathrm{m}}^{\prime}=9 \mathrm{kPa}-\varphi^{\prime} \mathrm{m}$ $=18.7^{\circ}$, which are about those reached post-peak in the shear tests on the clay samples, were found to provide $\mathrm{F}=1$. Therefore, these values have been used in all LE analyses port intervention.

To start with, a stability factor increment, $\Delta \mathrm{F}$, equal to $14 \%$ is reached for section $1-1^{\prime}$ after installation of a drainage trench system characterized by $\mathrm{n}=3, \mathrm{~S}=18 \mathrm{~m}$ and $\mathrm{H}_{0}=22 \mathrm{~m}\left(\mathrm{~S} / \mathrm{H}_{0}=0.82\right)$, whose plane of symmetry coincides with the section. Given $n=3$, Figure 20 outlines the variability of $\Delta \mathrm{F}$ with $\mathrm{S} / \mathrm{H}_{0}$ for the section 1-1'; in the plot, the contours of constant $\mathrm{S}$ (dashed lines) and constant $\mathrm{H}_{0}$ (solid lines) are indicated. $\Delta \mathrm{F}$ is found to increase mostly with increasing $\mathrm{H}_{0}$, in accordance with the increase in $\bar{E}$ discussed before. Furthermore, Figure 21 shows that the increment in stability factor increases with the number of trenches, due to the group effect, although the increment obtained passing from $n=5$ to $n=7$ is significantly lower than that calculated with the increment of $n$ from 3 to 5 .

Given the bowl shape of the Fontana Monte slip surface, the increment in stability factor $\Delta \mathrm{F}$ in Figures 20 and 21 for section $1-1^{\prime}$, are the minimum among the $\Delta \mathrm{F}$ achieved along the other sections, since in the latter the slip surface is shallower and, therefore, the increase in shear strength achieved through drainage is higher. In order to assess the variability of $\triangle \mathrm{F}$ among the 2D LE analyses carried out for the section 1-1' $2-2^{\prime}$, and 3-3', in Figure 22, $\Delta \mathrm{F}$ calculated for each $2 \mathrm{D}$ analysis has been renamed $2 \mathrm{D}-\Delta \mathrm{F}$ and has been plotted versus the distance of the longitudinal section from the central section of the landslide (which coincides with section $1-1^{\prime}$ ). The $2 \mathrm{D}-\Delta \mathrm{F}$ values in the figure refer to the case $\mathrm{n}$ $=5, \mathrm{H}_{0}=16 \mathrm{~m}$ and $\mathrm{S}=14 \mathrm{~m}$ (called "standard system"). In such analyses, the efficiency $\overline{\mathrm{E}}$ has been calculated in the different portions of the bowl-shaped slip surface according to the calculation strategy discussed in section 3 (Figure 9). The figure shows the increase in $2 \mathrm{D}-\Delta \mathrm{F}$ with the increasing distance of the calculation section from central section of the landside. 


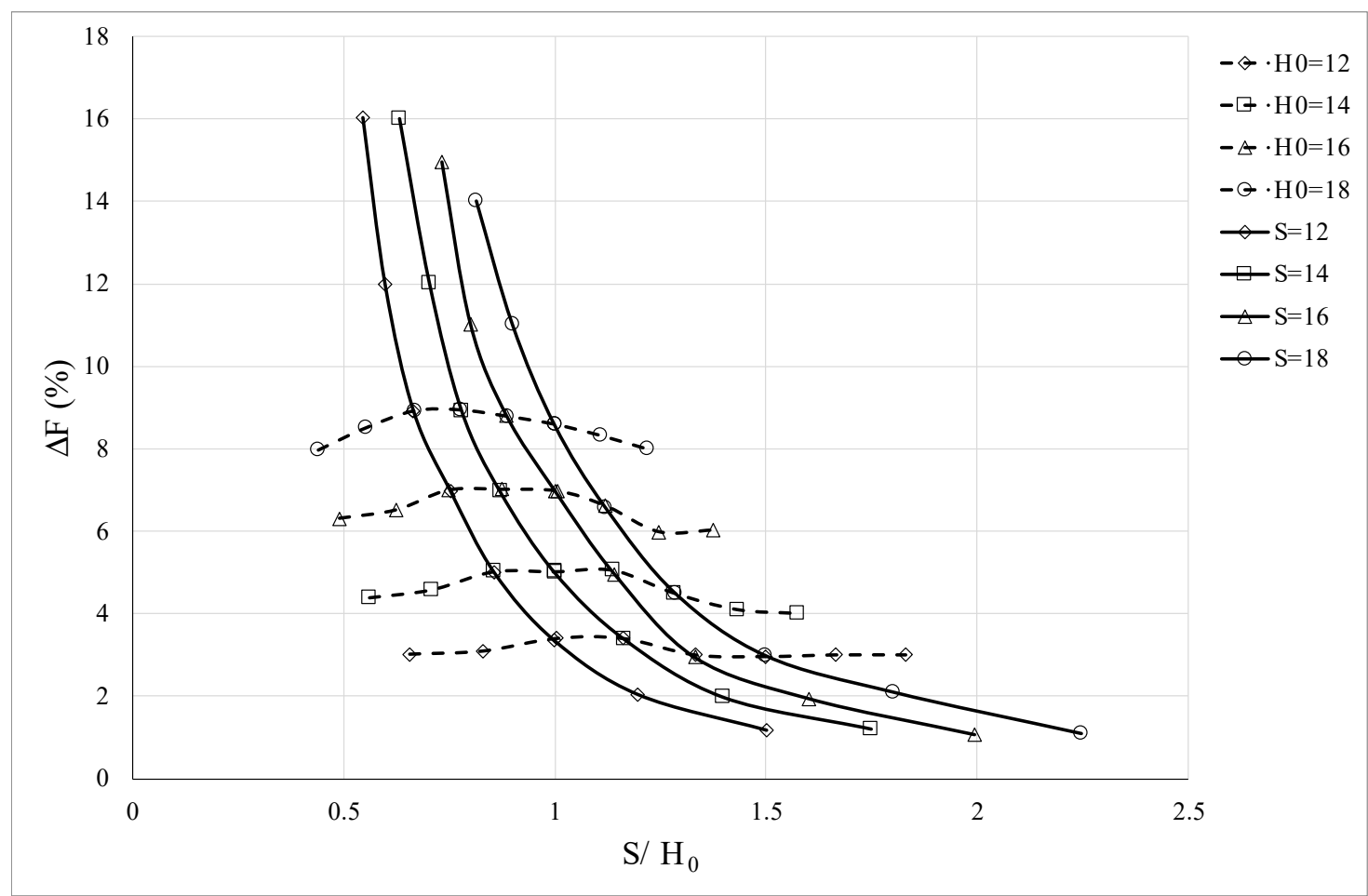

Figure 20. Increment of the stability factor $\Delta \mathrm{F}$ for section $1-1^{\prime}$ in Figure 19 when $\mathrm{n}=3$ ( $\mathrm{t}=5$ years).

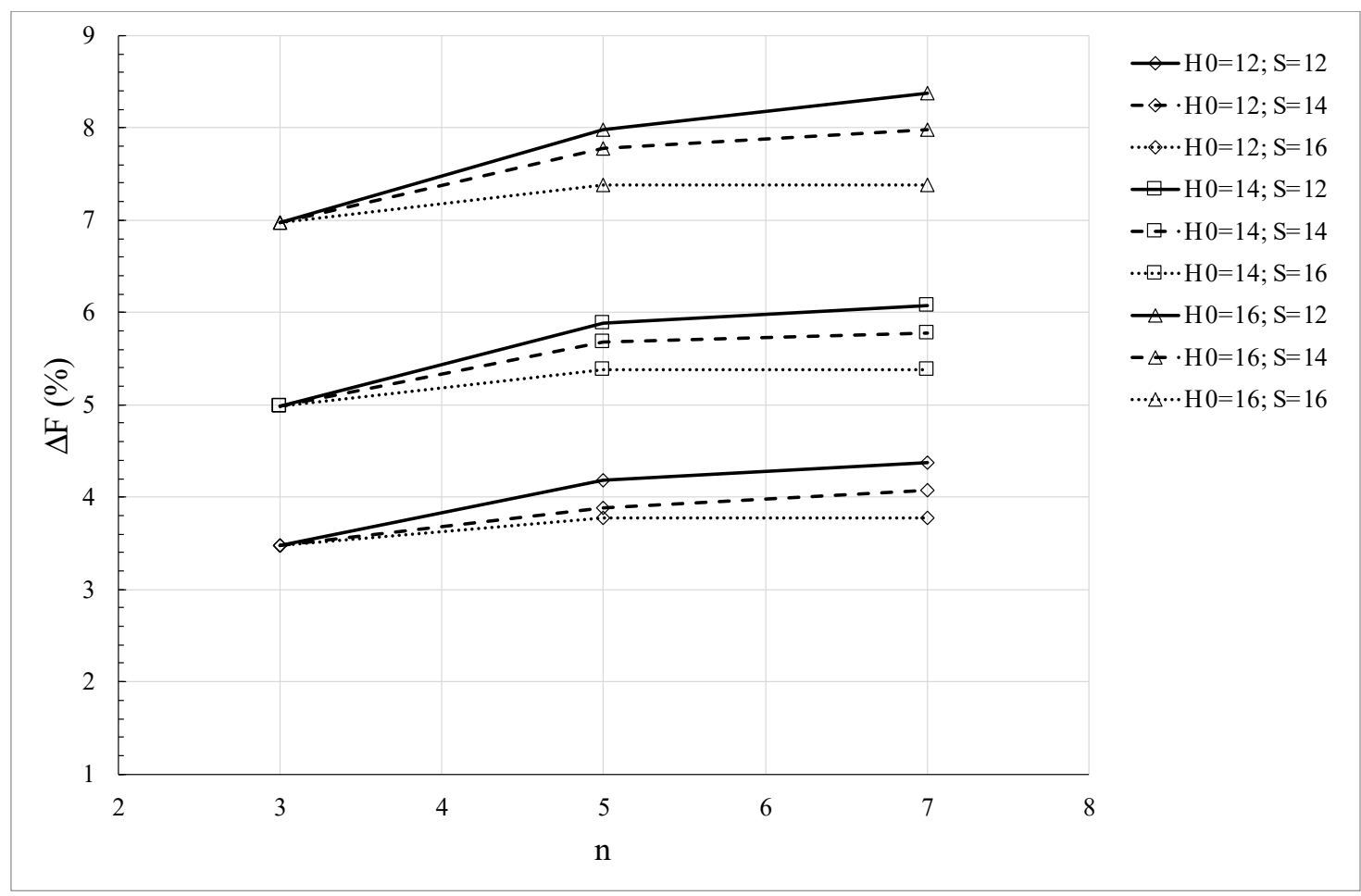

Figure 21. $\Delta \mathrm{F}$ against number of trenches $\mathrm{n}$, with different combinations of trench depth and trench spacing. 


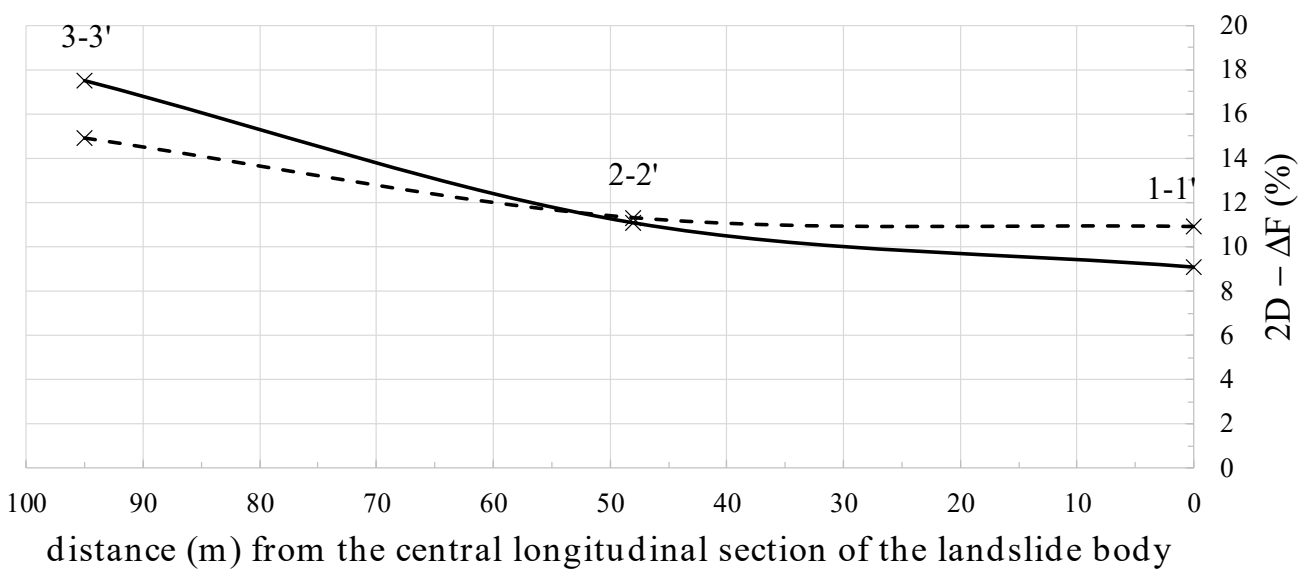

$\leftarrow$ standard system of constant trench depth (e.g. see Figure 10)

$-\star$ optimized system shown in Figure 23

Figure 22. Values of the stability factor in the three longitudinal sections $1-1^{\prime}, 2-2^{\prime}$, and $3-3^{\prime}$ in Figure 19a for the trench drainage system: $n=5, \mathrm{H}_{0}=16 \mathrm{~m}, \mathrm{~S}=14 \mathrm{~m}$, and for the optimized drainage system.

On the whole, the results suggest some criteria of optimization of the design of the drainage trench system. In particular, the installation of the system may be more sustainable and as efficient if including a smaller trench spacing, $\mathrm{S}$, and a larger trench depth, $\mathrm{H}_{0}$, in the area where the slip surface is deeper, i.e., in the middle of the landslide body. Conversely, in the lateral portions of the landslide, a larger spacing with shallower trenches can be used, as schematized in Figure 23. For example, a drainage trench system characterized by five trenches, with a spacing $S$ equal to $12 \mathrm{~m}$ and a depth $\mathrm{H}_{0}$ of $18 \mathrm{~m}$ in the middle, and a spacing $\mathrm{S}$ equal to $16 \mathrm{~m}$ with a depth $\mathrm{H}_{0}$ of $12 \mathrm{~m}$ at the boundaries, as shown in Figure 23, has been implemented in an additional seepage analysis.

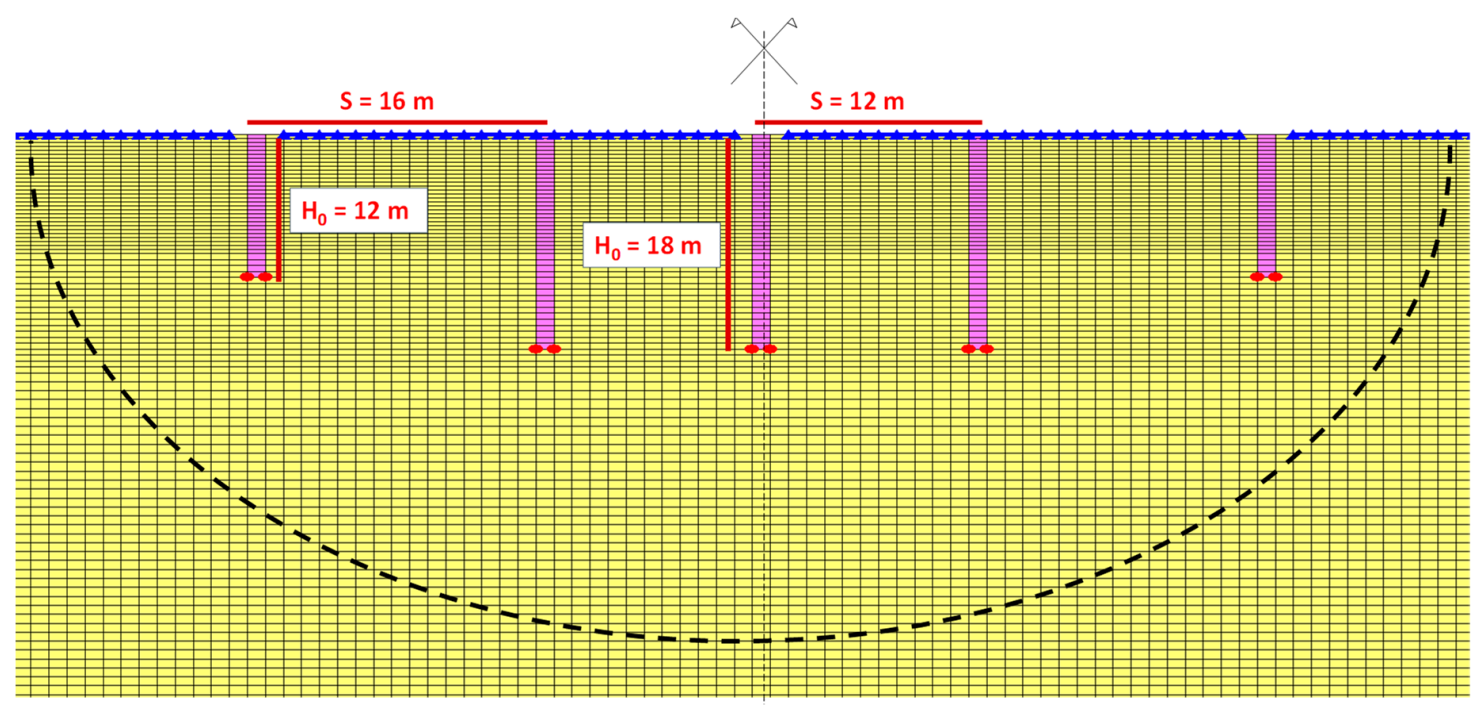

Figure 23. Numerical model for the proposed drainage system's design. 
The corresponding $2 \mathrm{D}-\Delta \mathrm{F}$ are reported in Figure 22, for comparison with the previous results. The comparison shows that the average stability factor obtained through this kind of drainage trench system, $\sim 13 \%$, is comparable to that reached with a standard system, of constant $\mathrm{S}$ and $\mathrm{H}_{0}$, but the system in Figure 23 is more sustainable, both in terms of costs and construction effort.

\section{Concluding Remarks}

The results of the study show the extent to which a properly designed drainage trench system may provide reasonable mitigation of the activity of deep landslide bodies, even in slopes formed of clays. Based on the analysis results, criteria for the optimization of the drainage trench system design have been proposed, for the stabilization of deep landslide bodies.

The new design procedure implements a more realistic account of the field seepage conditions. The comparison of the new analysis results with the $\overline{\mathrm{E}}$ predictions reported in previous studies shows that also at depth larger than the trench depth (e.g., up to double $\mathrm{H}_{0}$ ), results from models accounting for partially saturated conditions, unsteady boundary conditions at the ground level and finite number of trenches, differ from model results assuming full saturation and an infinite number of trenches. Furthermore, the new results give evidence to the uncoupled influence of $\mathrm{H}_{0}, \mathrm{n}$ and $\mathrm{S}$ on the $\overline{\mathrm{E}}$ values. Therefore, the present paper represents a step forward in the assessment of the influence of the geometric parameters of drainage trench systems and of the field hydraulic conditions (partially saturated conditions, initial water table location) on the increase in safety factor provided by the mitigation measure.

At large depths, the assessment of the efficacy of the intervention must account for the "group effect", which influences the pore pressure regime. The case study used for the validation of the design strategy has been the Fontana Monte landslide, whose geomorphology (bowl-shaped slip surface) and geotechnical parameters had been assessed in previous studies. The analysis results show that the geometric parameter $\mathrm{H}_{0}$ has a greater influence, than $\mathrm{n}$ and $\mathrm{S}$, on the pore water pressure reduction at the maximum depth of the slip surface. Moreover, the account for the variation in $\overline{\mathrm{E}}$ along the transversal sections of the bowl-shaped slip surface, allows for the recognition of the significant $3 \mathrm{D}-\Delta \mathrm{F}$ that the trench system provides, which is far higher than the $2 \mathrm{D}-\Delta \mathrm{F}$ calculated for the deepest longitudinal section of the slip surface. Based on the results, an optimization of the drainage system geometry has been proposed.

Author Contributions: Conceptualization, F.C. and R.P.; methodology, F.C. and P.L.; validation, R.P. and D.M.; formal analysis, R.P. and D.M.; resources, F.C.; data curation, D.M.; writing-original draft preparation, F.C. and R.P.; writing-review and editing, F.C. and D.M.; visualization, D.M.; supervision, P.L.; project administration, F.C.; funding acquisition, F.C. All authors have read and agreed to the published version of the manuscript.

Funding: This research was funded by the Italian Ministry for Research and University, PRIN 2015 grant (Prot. 201572YTLA).

Acknowledgments: We thank Francesca Santaloia (Italian Council of Research-IRPI) and Vito Tagarelli (DICATECH, Technical University of Bari) for their fundamental contribution to this work.

Conflicts of Interest: The authors declare no conflicts of interest.

\section{References}

1. Bianco, B. Interventi per la Riduzione Delle Pressioni Interstiziali nei Pendii Instabili; Geologia Applicata e Idrogeologia: Bari, Italy, 1979; Volume XIV/3.

2. Cotecchia, V. La Stabilità del Suolo in Italia: Zonazione Della Sismicità-Frane; Accademia Naz. dei Lincei: Roma, Italy, 1997; pp. 187-259. (In Italian)

3. Hutchinson, J.N. Assessment of the effectiveness of corrective measures in relation to geological conditions and types of slope movement. General report on theme 3, symposium on landslides and other mass movement, Prague. Bull. Int. Assoc. Eng. Geol. 1977, 16, 131-155. [CrossRef]

4. Sharp, J.C. Fluid Flow through Fissured Media. Ph.D. Thesis, Imperial College of London, London, UK, 1970. 
5. Vaciago, G. The SafeLand Compendium of Landslide Risk Mitigation Measures. In Landslide Science and Practice; Margottini, C., Canuti, P., Sassa, K., Eds.; Springer: Berlin/Heidelberg, Germany, 2013.

6. Cruden, D.M.; Varnes, D.J. Landslide types and processes. In Landslides_Investigation and Mitigation; Special Report 247; Turner, A.K., Schuster, L., Eds.; Transportation Research Board: Washington, DC, USA, 1996; pp. 36-75.

7. Lirer, S. Landslide stabilizing piles: Experimental evidences and numerical interpretation. Eng. Geol. 2012, 149, 70-77. [CrossRef]

8. Bjerrum, L. Progressive failure in slopes of overconsolidated plastic clay and clay shales. J. Soil Mech. Found. Div. 1967, 93, 1-49.

9. Terzaghi, K. Mechanism of landslides, in Application of geology to engineering practice. Geol. Soc. Am. 1950, 327, 83-123.

10. Cotecchia, F.; Pedone, G.; Bottiglieri, O.; Santaloia, F.; Vitone, C. Slope-atmosphere interaction in a tectonized clayey slope: A case study. Ital. Geotech. J. 2014, 1, 34-61.

11. Cotecchia, F.; Lollino, P.; Petti, R. Efficacy of drainage trenches to stabilise deep slow landslides in clay slopes. Géotechnique Lett. 2016, 6, 1-6. [CrossRef]

12. Pun, W.K.; Urciuoli, G. Soil nailing and subsurface drainage for slope stabilization. In Proceedings of the 10th international symposium on landslides and engineering slopes, Xian, China, 30 June-4 July 2008.

13. Stanic, B. Influence of drainage trenches on slope stability. J. Geotech. Eng. 1984, 110, 1624-1635. [CrossRef]

14. Meriggi, R.; Ziraldo, A. Effects of trench drains on slope stability during heavy rainfalls. In Landslides: Evaluation and stabilization, International Symposium on Landslides, Rio de Janeiro, Brazil, 28 June 2004; Lacerda, W.A., Ed.; Balkema, A.A.: Leiden, The Netherlands, 2004; pp. 1677-1683.

15. Whitely, H.M. Earthwork slips on the Castle Eden and Stockton Railway. Min. Proc. Instn Civil Eng. 1880, 62, 280-284. [CrossRef]

16. Desideri, A.; Rampello, S. Stabilizzazione dei pendii mediante sistemi di drenaggio. In Mitigazione del Rischio Mediante Interventi di Consolidamento e Rinforzo dei Terreni, Conferenze di Geotecnica di Torino; Patron Editore: Bologna, Itaty, 2009; pp. 1-48.

17. Di Maio, C.; Santagata, P.; Viggiani, C. Analisi del processo di consolidazione indotto da un sistema di trincee drenanti. In Proceedings of the XVI Convegno Nazionale di Geotecnica, Bologna, Italy, 14-16 May 1986; pp. 283-289.

18. Urciuoli, F.; Pirone, M. Subsurface Drainage for Slope Stabilization; ASCE Press: Reston, VA, USA, 2013; Volume 6.

19. D'Acunto, B.; Urciuoli, G. Groundwater regime in a slope stabilised by drain trenches. Math. Comput. Model. 2006, 53, 754-765. [CrossRef]

20. Marzulli, V.; Cafaro, F.; Ziccarelli, M. Hydraulic Characterization of a Pervious Concrete for Deep Draining Trenches. J. Mater. Civil Eng. 2018, 30, 04018100. [CrossRef]

21. Valore, C.; Ziccarelli, M.; Muscolino, S.R. An experimental investigation into the permeability and filter properties of pervious concrete for deep draining trenches. Ital. Geotech. J. 2017, 52, 7-30.

22. Cotecchia, F.; Vitone, C.; Santaloia, F.; Pedone, G.; Bottiglieri, O. Slope instability processes in intensely fissured clays: Case histories in the Southern Apennines. Landslides 2014, 12, 877-893. [CrossRef]

23. Cotecchia, F.; Tagarelli, V.; Pedone, G.; Ruggieri, G.; Guglielmi, S.; Santaloia, F. Analysis of climate-driven processes in clayey slopes for the early-warning system design. Proc. Inst. Civil Eng. Geotech. Eng. 2019, 172, 465-780. [CrossRef]

24. Tagarelli, V.; Cotecchia, F. Deep Movements in Clayey Slopes Relating to Climate: Modeling for Early Warning System Design. Research for Land Protection and Development. CNRIG 2019. Lect. Notes Civil Eng. 2020, 40. [CrossRef]

25. Tagarelli, V.; Cotecchia, F. The Effects of Slope Initialization on the Numerical Model Predictions of the Slope-Vegetation-Atmosphere Interaction. Geosciences 2020, 10, 85. [CrossRef]

26. Cotecchia, F.; Santaloia, F.; Lollino, P.; Vitone, C.; Mitaritonna, G. Deterministic landslide hazard assessment at regional scale. Geoflorida 2010. In Proceedings of Advances in Analysis, Modelling \& Design; ASCE Geotechnical Special Publication: West Palm Beach, FL, USA, 2010; pp. 3130-3139.

27. Hutchinson, J.N. Review of flow-like mass movements in granular and fine-grained materials. In Proceedings of the International Workshop "Ocurrence and Mechanisms of Flow-Like Landsilds in Natural Slopes and Earthfills", Sorrento, Italy, 14-16 May 2003; Picarelli, L., Ed.; Patron Editore: Bologna, Itaty, 2004; pp. 3-16. 
28. Cotecchia, F.; Santaloia, F.; Lollino, P.; Vitone, C.; Pedone, G.; Bottiglieri, O. From a phenomenological to a geomechanical approach to landslide hazard analysis. Eur. J. Civil Environ. Eng. 2016, 20, 1004-1031. [CrossRef]

29. Pedone, G. Interpretation of Slow and Deep Landslides Triggered by Slope-Atmosphere Interaction in Slopes Formed of Fissured Clayey Turbidites. Ph.D. Thesis, Polytecnical University of Bari, Bari, Italy, 2014.

30. Lollino, P.; Cotecchia, F.; Elia, G.; Mitaritonna, G.; Santaloia, F. Interpretation of landslide mechanisms based on numerical modelling: Two case histories. Eur. J. Civil Environ. Eng. 2014, 20, 1032-1053. [CrossRef]

31. Burghignoli, A.; Desideri, A. Analisi dei moti di filtrazione indotti dall'esecuzione di scavi e trincee. In Atti XV Conv. Nazionale di Geotecnica, Spoleto; Patron Editore: Bologna, Italy, 1983; pp. 51-56.

32. Geo-Studio. SEEP/W and SLOPE/W codes. User's manual; Geo-Studio: Calgary, AB, Canada, 2004.

33. Mualem, Y. A new model for predicting the hydraulic conductivity of unsaturated porous media. Water Resour. Res. 1976, 12, 513-522. [CrossRef]

34. Van Genuchten, M.T. A closed form equation for predicting the hydraulic conductivity of unsaturated soils. Soil Sci. Soc. Am. J. 1980, 44, 892-898. [CrossRef]

35. Cafaro, F.; Cotecchia, F. Structure degradation and changes in the mechanical behaviour of a stiff clay due to weathering. Géotechnique 2001, 51, 441-453. [CrossRef]

36. Bottiglieri, O.; Cafaro, F.; Cotecchia, F. Estimating the retention curve of a compacted soil through different testing and interpretation methods. In Unsaturated Soils: Research and Applications; Mancuso, C., Jommi, C., D’Onza, F., Eds.; Springer: Berlin/Heidelberg, Germany, 2012; Volume 1, pp. 47-54.

37. Lollino, P.; Elia, G.; Cotecchia, F.; Mitaritonna, G. Analysis of landslide reactivation mechanisms in Daunia clay slope by means of limit equilibrium and FEM methods. In Proceedings of the Advances in Analysis, Modelling \& Design, West Palm Beach, FL, USA, 20-24 February 2010; pp. 3155-3164.

38. Morgenstern, N.R.; Price, V.E. The analysis of the stability of general slip surface. Géotechnique 1965, 15, $239-247$. [CrossRef]

(C) 2020 by the authors. Licensee MDPI, Basel, Switzerland. This article is an open access article distributed under the terms and conditions of the Creative Commons Attribution (CC BY) license (http://creativecommons.org/licenses/by/4.0/). 